\title{
Direct observation of layered-to- spinel phase transformation in Li2MnO3 and the spinel structure stabilised after the activation process
}

\section{AUTHOR(S):}

Shimoda, Keiji; Oishi, Masatsugu; Matsunaga, Toshiyuki; Murakami, Miwa; Yamanaka, Keisuke; Arai, Hajime; Ukyo, Yoshio; ... Ohta, Toshiaki; Matsubara, Eiichiro; Ogumi, Zempachi

\section{CITATION:}

Shimoda, Keiji ...[et al]. Direct observation of layered-to-spinel phase transformation in $\mathrm{Li} 2 \mathrm{MnO} 3$ and the spinel structure stabilised after the activation process. Journal of Materials Chemistry A 2017, 5(14): 6695-6707

\section{ISSUE DATE:}

2017-05-02

\section{URL:}

http://hdl.handle.net/2433/224984

\section{RIGHT:}

This is the accepted version of the article, which has been published in final form at

http://dx.doi.org/10.1039/c6ta11151c.; The full-text file will be made open to the public on 02 May 2018 in accordance with publisher's 'Terms and Conditions for Self-Archiving'.; この論文は出版社版でありません。引用の際には出版社版 をご確認ざ利用ください。; This is not the published version. Please cite only the published version. 


\title{
Direct Observation of Layered-to-Spinel Phase Transformation in $\mathrm{Li}_{2} \mathrm{MnO}_{3}$ and Spinel Structure Stabilised after the Activation Process $\dagger$
}

Keiji Shimoda, ${ }^{* a}$ Masatsugu Oishi, $\ddagger^{\mathrm{a}}$ Toshiyuki Matsunaga, ${ }^{\mathrm{a}}$ Miwa Murakami, ${ }^{\mathrm{a}}$ Keisuke Yamanaka, ${ }^{\mathrm{b}}$ Hajime Arai, ${ }^{\mathrm{a}}$ Yoshio Ukyo, ${ }^{\mathrm{a}}$ Yoshiharu Uchimoto, ${ }^{\mathrm{c}}$ Toshiaki Ohta, ${ }^{\mathrm{b}}$ Eiichiro Matsubara, ${ }^{\mathrm{d}}$ Zempachi Ogumi $^{\mathrm{a}}$

${ }^{a}$ Office of Society-Academia Collaboration for Innovation, Kyoto University, Uji, Kyoto 611-0011, Japan

${ }^{b}$ SR Censter, Ritsumeikan University, Kusatsu, Shiga 525-8577, Japan

${ }^{c}$ Graduate School of Human and Environment Studies, Kyoto University, Kyoto 606-8501, Japan

${ }^{d}$ Department of Materials Science and Engineering, Kyoto University, Kyoto 606-8501, Japan

‡ Present address: Institute of Science and Technology, Tokushima University, Tokushima 770-8506, Japan

\begin{abstract}
$\mathrm{Li}_{2} \mathrm{MnO}_{3}$ is an important parent component in the lithium- and manganese-rich layered oxides (LMRs), which are one of the promising positive electrode materials for the next-generation lithium ion rechargeable batteries. Here, we report the layered-to-spinel phase transformation in $\mathrm{Li}_{2} \mathrm{MnO}_{3}$ during the initial charging process to characterise its unique delithiation behaviour, which gives an insight into the relationship between the structure, superior capacities and degradation of the LMR electrodes. The atomic-scale observation using scanning transmission electron microscopy (STEM) techniques suggests that the structural transformation occurs in a
\end{abstract}


biphasic manner within a single particle. The formed phase has a Li-defect spinel structure, indicating that the delithiation leads to Mn migration from the transition-metal layer to the $\mathrm{Li}$ layer, accompanied with some oxygen release. This layered-to-spinel phase transformation is an essential bulk process in the initial activation of $\mathrm{Li}_{2} \mathrm{MnO}_{3}$. During the lithiation in the $1^{\text {st }}$ discharging, the Mn remigration occurs and the layered structure is again formed with significant disordering. During the multiple cycles, the defect spinel structure is stabilised and becomes more oxygen-deficient with lower Mn valence. As a consequence, the amount of inserted Li decreases, which corresponds to the capacity and voltage fading observed in $\mathrm{Li}_{2} \mathrm{MnO}_{3}$ and the LMRs.

† Electronic supplementary information (ESI) available. See ***.

Keywords: Lithium-ion rechargeable batteries, $\mathrm{Li}_{2} \mathrm{MnO}_{3}$, scanning transmission electron microscopy, electron energy loss spectroscopy.

*Corresponding author:

Keiji Shimoda

Gokashou, Uji 611-0011, Japan

Office of Society-Academia Collaboration for Innovation, Kyoto University

E-mail address: k-shimoda@saci.kyoto-u.ac.jp

Tel: +81-774-38-4967

Fax: +81-774-38-4996 


\section{Introduction}

Lithium ion rechargeable batteries (LIBs) have been widely used as a power source for portable devices. On the other hand, its wide applications to electric vehicles (EVs) further demand high power, high energy density, long life, low cost, and safe batteries. The most successful positive electrode materials are layered transition-metal oxides, $\mathrm{LiCoO}_{2}$ and its derivatives, with their electrochemical capacities of ca. $150 \mathrm{~mA} \mathrm{~h} \mathrm{~g}$ up to a practical potential of $4.2 \mathrm{~V} \mathrm{vs.} \mathrm{Li}^{-1} \mathrm{Li}^{+}$. Lithium- and manganese-rich layered oxides (LMRs), commonly described as a composite $x \mathrm{Li}_{2} \mathrm{MnO}_{3} \cdot(1-x) \mathrm{Li} \mathrm{O}_{2}(M=\mathrm{Ni}, \mathrm{Co}$, etc.), have been extensively studied as a prefered candidate material for the next-generation LIB positive electrodes because they show high reversible capacities beyond $200 \mathrm{~mA} \mathrm{~h} \mathrm{~g}^{-1} .^{2-9}$ It is well known that LMRs show a characteristic irreversible voltage plateau at ca. $4.5 \mathrm{~V}$ vs. $\mathrm{Li} / \mathrm{Li}^{+}$in the initial charging process. This plateau is considered to come from the activation of the nominally inactive $\mathrm{Li}_{2} \mathrm{MnO}_{3}$ component in the materials. Therefore, understanding the delithiation mechanism of the end-member component $\mathrm{Li}_{2} \mathrm{MnO}_{3}$ should be an important clue to elucidate the origin of the superior capacities of LMRs and also the origin of the deterioration after the multiple charge-discharge cycles. This information will be helpful to improve their electrochemical performance.

$\mathrm{Li}_{2} \mathrm{MnO}_{3}$, also described as $\mathrm{Li}\left[\mathrm{Li}_{1 / 3} \mathrm{Mn}_{2 / 3}\right] \mathrm{O}_{2}$, has a layered structure with the space group of $C 2 / m \cdot{ }^{10,11} \mathrm{Li}$ ions occupy not only the Li layer but also the transition-metal (TM) layer with intralayer ordering between $\mathrm{Li}$ and $\mathrm{Mn}$ ions, giving the theoretical capacity of $459 \mathrm{~mA} \mathrm{~h} \mathrm{~g}^{-1}$. The electrochemical profile of $\mathrm{Li}_{2} \mathrm{MnO}_{3}$ has a voltage plateau at ca. $4.5 \mathrm{~V}$ vs. $\mathrm{Li} / \mathrm{Li}^{+}$in the initial charge and shows a large irreversible capacity in the subsequent discharge. ${ }^{12}$ There have been some controversial reports about the charge compensation mechanism on the delithiation from $\mathrm{Li}_{2} \mathrm{MnO}_{3}$. Firstly, the increase in $\mathrm{Mn}$ valence from +4 to +5 had been speculated for charge

compensation, ${ }^{13}$ but the subsequent reports suggested that the oxidation state of $\mathrm{Mn}$ ions remains 
unchanged based on the Mn K-edge X-ray absorption fine structure (XAFS) spectra. ${ }^{14-16}$ Alternatively, Dahn et al. proposed a simultaneous lithium and oxygen removal from the structure. ${ }^{17}$ The oxygen removal seems consistent with a large irreversible capacity observed in the initial charge-discharge cycle. Yu et al. showed a significant amount of $\mathrm{O}_{2}$ release from the electrode, but they also pointed out that it merely accounts for about a half of the observed capacity in $\mathrm{Li}_{2} \mathrm{MnO}_{3} \cdot{ }^{14}$ On the other hand, the first-principles calculations have indicated that the oxidation of oxygen anion $\left(\mathrm{O}^{2-} / \mathrm{O}^{-}\right.$redox couple) without $\mathrm{O}_{2}$ release can explain the characteristic voltage plateau of $\mathrm{Li}_{2} \mathrm{MnO}_{3}{ }^{18,19}$ Then, the formation of the peroxo-like species were experimentally suggested in the chemically-delithiated $\mathrm{Li}_{2} \mathrm{MnO}_{3}$ after the important studies provided by Tarascon and coworkers, who used the O 1s X-ray photoelectron spectroscopy (XPS) to examine the oxidation states of oxygen anions in the charged and discharged Li-rich layered oxide electrodes. ${ }^{20-22}$ Also, we have suggested the redox contribution of oxygen anions in the $\mathrm{Li}_{2} \mathrm{MnO}_{3}$ bulk structure and its reversible behaviour on charge-discharge cycles by using the $\mathrm{O}$ K-edge XAFS spectroscopy. ${ }^{23}$

On the other hand, structural phase transformation during the delithiation process has been still unclear because the reported X-ray diffraction (XRD) profiles showed significant decreases in diffraction intensity, indicating a severe lattice disordering by the lithium extraction, ${ }^{14}$ which makes structural characterisation difficult. Some studies reported weak diffraction peaks attributable to spinel structure in the partially delithiated $\mathrm{Li}_{2} \mathrm{MnO}_{3}{ }^{24,25}$ Recent advances in scanning transmission electron microscopy (STEM) techniques have offered a chance to gain the atomic column images for the delithiated/relithiated electrode materials. ${ }^{26-28}$ Wang et al. observed the Mn migration from the TM layer to the $\mathrm{Li}$ layer in $\mathrm{Li}_{2} \mathrm{MnO}_{3}$ charged to $4.8 \mathrm{~V}$ in the initial cycle, which was considered as a direct evidence of the formation of spinel-like domain during delithiation. ${ }^{29}$ They further reported that the Mn occupancy in the Li layer disappeared in the 
relithiated sample. Also, the spinel domains were observed at the particle surface in the $10^{\text {th }}$ cycled discharged $\mathrm{Li}_{2} \mathrm{MnO}_{3}$ electrode sample, whereas the $C 2 / m$ lattice structure was preserved in the bulk region. ${ }^{30,31}$ These studies concluded that the formation of spinel phase was a consequence of structural degradation and highly localised at the particle surface and the limited region in the bulk. Croy et al. investigated the structural evolutions of $\mathrm{Li}$ and $\mathrm{Mn}$ local environments in between the pristine $\mathrm{Li}_{2} \mathrm{MnO}_{3}$ and electrode samples charged to $5.0 \mathrm{~V}$ and discharged to $2.0 \mathrm{~V}$ by using solid-state nuclear magnetic resonance (NMR) and extended X-ray absorption fine structure (EXAFS) analyses. ${ }^{16}$ They reported that the lithium extraction from both the Li and TM layers and the subsequent reinsertion into both the layers for the charged and discharged samples, respectively. A substantial reduction of $\mathrm{Mn}$ valence from $\mathrm{Mn}^{4+}$ to $\mathrm{Mn}^{3+}$ with the Jahn-Teller distorted coordination environments was also suggested in the discharged material. Although these studies have provided important suggestions about the structural changes of $\mathrm{Li}_{2} \mathrm{MnO}_{3}$ on the initial delithiation/relithiation process, some details are still open to debate. The important mysteries are the process how the $\mathrm{Li}$ ions are deintercalated from the lattice (single-phase or two-phase reaction) and the crystal structure after the full extraction of Li ions in $\mathrm{Li}_{2} \mathrm{MnO}_{3}$. In this article, we report the phase transformation occuring in the $\mathrm{Li}_{2} \mathrm{MnO}_{3}$ lattice structure during the initial charge-discharge cycle and propose the two-phase delithiation mechanism on the charging process on the basis of the high angle annular dark field (HAADF) STEM observation coupled with electron energy loss spectroscopy (EELS). The lattice structures of the active materials in the $20^{\text {th }}$ discharged and $21^{\text {st }}$ charged electrodes are also characterised, which relates the degraded structure to the capacity and voltage fading during the prolonged electrochemical operation.

\section{Experimental}


$\mathrm{Li}_{2} \mathrm{MnO}_{3}$ was synthesised by a solid-state reaction at $700{ }^{\circ} \mathrm{C}$ for $12 \mathrm{~h}$ with the starting materials $\mathrm{LiOH} \cdot \mathrm{H}_{2} \mathrm{O}$ (Wako Pure Chemical Industries) and $\mathrm{MnCO}_{3}$ (Kojundo Chemical Laboratory) in a molar ratio of $2.1: 1.0$. The details are described elsewhere. ${ }^{32}$ The obtained particle size was estimated to be ca. $2 \mu \mathrm{m}$ on average, which consisted of small crystallites of ca. $100 \mathrm{~nm}$ in diameter. The chemical composition was confirmed from the inductively coupled plasma-atomic emission spectrometry (ICP-AES, ICPS-8100, Shimadzu), and the average Mn oxidation state was estimated from the iodometric titration measurements.

A positive electrode was prepared from a mixture of $\mathrm{Li}_{2} \mathrm{MnO}_{3}$, acetylene black (Denki Kagaku Kogyo), and polyvinylidene difluoride (PVDF, Kureha) in a weight ratio of $80: 10: 10$, which was spread onto an aluminium foil with 1-methyl-2-pyrrolidone (NMP) and then dried at $80{ }^{\circ} \mathrm{C}$ under vacuum overnight. The electrode was pressed to a typical thickness of $35-40 \mu \mathrm{m}$. A foil of metallic lithium (0.2 mm in thickness, > 99.9\%, Honjo Metal) was used as counter and reference electrodes. These components were assembled together with the Celgard 2500 separator and soaked in the electrolyte solution, which were sealed in an aluminium-coated laminate-type cell in an Ar-filled glove box. The electrolyte solution was $1 \mathrm{M} \mathrm{LiPF}_{6}$ solution dissolved in anhydrous ethylene carbonate (EC) and ethylmethyl carbonate (EMC) with a volumetric ratio of $3: 7$ (Kishida Chemical).

Electrochemical measurements were performed at $50{ }^{\circ} \mathrm{C}$ on an automatic cycling and data recording system (HJ1001SD8, Hokuto Denko). The cells were galvanostatically cycled between 4.8 and $2.0 \mathrm{~V}$ vs. $\mathrm{Li} / \mathrm{Li}^{+}$at a current rate of $23 \mathrm{~mA} / \mathrm{g}$. The cells were carefully disassembled at desired states of charge/discharge in the glove box and rinsed with dimethyl carbonate (DMC) to remove the electrolyte solution residue.

Synchrotron radiation powder XRD (SR-XRD) measurements were carried out for the 
disassembled samples sealed in $0.5 \mathrm{~mm} \phi$ borosilicate glass capillaries in the $2 \theta$ range of $4.2^{\circ}-$ $77.8^{\circ}$ with $\Delta \theta$ of $0.003^{\circ}$ at the BL28XU beamline at SPring-8 (Hyogo, Japan). The incident radiation of $\lambda=0.500 \AA$ and two-dimensional X-ray detector PILATUS (DECTRIS) was applied. The acquired $2 \theta$ datasets were converted to ones corresponding to the Mo $K \alpha$ wavelength $(\lambda=$ $0.709 \AA ̊)$.

${ }^{6}$ Li MAS NMR spectra were acquired on a DD2 600 spectrometer at a magnetic field of 14.1 T with a wide-bore T3 MAS probe (Agilent Technologies). The powdered samples were packed into $1.2 \mathrm{~mm} \phi$ MAS $\mathrm{ZrO}_{2}$ rotors with airtight caps, which were spun at a spinning rate of $50 \mathrm{kHz}$ during the experiments. The practical temperatures of spinning samples at $50 \mathrm{kHz}$ were estimated to be ca. $60{ }^{\circ} \mathrm{C}$ due to frictional heating. A rotor-synchronised Hahn echo pulse sequence ( $\pi / 2-\tau-\pi-\tau$-acq.) was used with the $\pi / 2$ pulse width of $0.9 \mu$ s and a relaxation delay of $0.1 \mathrm{~s}$. All spectra were referenced to $1 \mathrm{M} \mathrm{LiCl}$ solution at $0.0 \mathrm{ppm}$.

Atomic column images were obtained by using the Cs-corrected scanning transmission microscope JEM-ARM200F (JEOL) operated at $200 \mathrm{kV}$. The samples were thin-sliced to less than $100 \mathrm{~nm}$ in thickness with focused ion beam (FIB, nanoDUET NB5000, HITACHI High-Technologies) and placed on a copper mesh and then transferred into the microscope. All these treatments were performed under vacuum or Ar atmosphere. The high angle annular dark field (HAADF) images were collected with the probe current of 8 pA and the collection semiangle of $42-168$ mrad. The spatial resolution of the microscope is defined as ca. $0.1 \mathrm{~nm}$ with the electron beam convergence semiangle of 14 mrad. Electron energy loss spectroscopy (EELS) and energy dispersive X-ray spectrometry (EDS) analyses were carried out on GIF Quantum-ER energy filter (Gatan) and JED-2300T (JEOL), respectively, which were equipped on the microscope. The EELS mapping measurements were performed with the probe current of $22 \mathrm{pA}$ 
and the collection semiangle of $71 \mathrm{mrad}$. The exposure time was 0.05 s per pixel $(1$ pixel $=2 \times 2$ $\mathrm{nm}^{2}$ in dimension) for $\mathrm{Li}$ and $0.25 \mathrm{~s}$ for $\mathrm{O}$ and $\mathrm{Mn}$, respectively. The energy resolution was 1.25 $\mathrm{eV}$.

\section{Results and discussion}

\subsection{Phase transformation in $\mathrm{Li}_{2} \mathrm{MnO}_{3}$ during the $1^{\text {st }}$ charge-discharge cycle}

Fig. 1 shows the charge-discharge profile of $\mathrm{Li}_{2} \mathrm{MnO}_{3}$ for the $1^{\text {st }}$ cycle. The sampling points for structural analyses are marked on the figure and also listed in Table S1. An irreversible voltage plateau is observed at ca. $4.5 \mathrm{~V}$ on the charging process. The charging and discharging capacities delivered at $50{ }^{\circ} \mathrm{C}$ are 442 and $214 \mathrm{~mA} \mathrm{~h} \mathrm{~g}^{-1}$, respectively. Almost the full extraction of Li ions is achieved by the electrochemical measurements at high temperature.

Fig. 2 shows the SR-XRD profiles for the $1^{\text {st }}$ cycle. The pristine $\mathrm{Li}_{2} \mathrm{MnO}_{3}$ sample can be indexed with the space group of $C 2 / m$ and the refined lattice parameters of $a=4.9259 \AA, b=$ $8.5283 \AA, c=5.0116 \AA$, and $\beta=109.125^{\circ}$ (Fig. S1a†). ${ }^{32}$ During the charging to $4.8 \mathrm{~V}$, all the diffraction intensities are monotonously decreased and broadened, indicating that the delithiation from $\mathrm{Li}_{2} \mathrm{MnO}_{3}$ results in a highly disordered material. Close inspection on the strongest 001 diffraction peak reveals that a shoulder peak appears and grows at higher diffraction angle with increasing the charging depth to 230 and $345 \mathrm{~mA} \mathrm{~h} \mathrm{~g}^{-1}$, and finally the diffraction peak settles at the highest angle of $2 \theta=8.83^{\circ}$ for the sample charged to $4.8 \mathrm{~V}$ (Fig. 2, inset). This suggests that the delithiation proceeds in a two-phase reaction mechanism. The previous studies reported the appearance of the diffraction peaks attributable to cubic/tetragonal spinel phases for the charged samples. $^{24,25}$ Some diffraction peaks observed in the present study (Sp. \#5) are close in position to those for Li-poor cubic spinel $\mathrm{Li}_{\delta \sim 0.05} \mathrm{Mn}_{2} \mathrm{O}_{4}\left(\lambda-\mathrm{MnO}_{2}\right.$, Fig. S1b $\left.\dagger\right),{ }^{33}$ although they are also similar to those of the P3-type stacking $(R-3 m)$ structure. ${ }^{34}$ The electrode sample charged to $4.8 \mathrm{~V}$ shows 
almost no residual peaks of the pristine $\mathrm{Li}_{2} \mathrm{MnO}_{3}$, being consistent with the observed charging capacity of $442 \mathrm{~mA} \mathrm{~h} \mathrm{~g}^{-1}$ (relative to the theoretical capacity, $459 \mathrm{~mA} \mathrm{~h} \mathrm{~g}^{-1}$ ).

When Li ions are reinserted into the material with the voltage down to $2.0 \mathrm{~V}$, the diffraction peaks are close to the original positions for $\mathrm{Li}_{2} \mathrm{MnO}_{3}$ but with the reduced intensities (Sp. \#7). This suggests that the material partly comes back to $\mathrm{Li}_{2} \mathrm{MnO}_{3}$ structure with low crystallinity. It is noteworthy that about a half of Li ions should be in the material discharged to $2.0 \mathrm{~V}$ according to the observed discharging capacity (Table S1), but its diffraction intensities are lower than those for the sample charged to $230 \mathrm{~mA} \mathrm{~h}^{-1}$ (Sp. \#3).

Fig. 3 shows the ${ }^{6} \mathrm{Li}$ MAS NMR spectra for the $1^{\text {st }}$ cycle. The pristine $\mathrm{Li}_{2} \mathrm{MnO}_{3}$ electrode sample shows three isotropic shifts (Sp. \#1). The minor sharp signal at ca. $0 \mathrm{ppm}$ comes from the impurity phase such as $\mathrm{Li}_{2} \mathrm{CO}_{3}$. The predominant signal at $728 \mathrm{ppm}$ with a shoulder at ca. 760 ppm is assigned to the $\mathrm{Li}$ ions in the Li layer (4h and $2 c$ in Wyckoff position, respectively) and the other at $1476 \mathrm{ppm}$ is attributable to the TM layer ( $2 b$ in Wyckoff position) in $\mathrm{Li}_{2} \mathrm{MnO}_{3}{ }^{35-37}$ On the charging process, the peak positions remain unchanged, but the signal intensities decrease monotonously. The Li ions are deintercalated from both the Li and TM layers (Fig. 3, inset). The sample disassembled at $4.8 \mathrm{~V}$ shows almost no signal, being consistent with the observed charging capacity. These results can be reasonably explained by the two-phase delithiation model between $\mathrm{Li}_{2} \mathrm{MnO}_{3}$ and $\mathrm{Li}$-poor phase(s). Although the Li-poor phase(s) cannot be identified from the ${ }^{6} \mathrm{Li} \mathrm{NMR}$ technique, the $\mathrm{Li}$-poor cubic spinel $\mathrm{Li}_{\delta \sim 0.05} \mathrm{Mn}_{2} \mathrm{O}_{4}$ is invoked based on the above XRD result and the HAADF-STEM results as discussed below. On the discharging process, some of $\mathrm{Li}$ ions are reinserted into both the $\mathrm{Li}$ and $\mathrm{TM}$ layers in $\mathrm{Li}_{2} \mathrm{MnO}_{3}$. Therefore, some domains of the $\mathrm{Li}$-poor spinel phase revert to the pristine $\mathrm{Li}_{2} \mathrm{MnO}_{3}$ structure. This is consistent with the XRD result. We here notice that in the ${ }^{6} \mathrm{Li}$ NMR spectrum of the sample discharged to $2.0 \mathrm{~V}$ (Sp \#7) the signal intensities are significantly reduced compared to the Li content estimated from the 
electrochemical measurements (Fig. 3, inset). The actual Li content in the sample discharged to 2.0 V was confirmed by ICP-AES to be almost identical to the one from the electrochemical measurement. All the reintercalated ${ }^{6} \mathrm{Li}$ signals should be observed (semi-) quantitatively in the spectrum, even if the material is highly disordered, because the ${ }^{6} \mathrm{Li}$ signals for the known Li-Mn-O materials $\left(\mathrm{LiMn}_{2} \mathrm{O}_{4}, \mathrm{Li}_{4} \mathrm{Mn}_{5} \mathrm{O}_{12}, \mathrm{Li}_{2} \mathrm{Mn}_{2} \mathrm{O}_{4}\right.$, and layered $\left.\mathrm{LiMnO}_{2}\right)$ are in the chemical shift range between 0 and 2000 ppm. ${ }^{38-40}$ We also observed an increase of the signal at ca. 0 ppm for the sample discharged at $2.0 \mathrm{~V}$, which is attributed to the solid electrolyte interphase (SEI) components such as $\mathrm{Li}_{2} \mathrm{CO}_{3}$ and $\mathrm{LiF}^{41,42}$ However, it does not fully account for the difference in Li content between the NMR and electrochemical measurements (Fig. 3, inset), even if the spectrum is acquired with the long relaxation delay of $20 \mathrm{~s}$. Therefore, we speculate that the apparent signal loss is due to severe broadening of ${ }^{6} \mathrm{Li}$ signal by the strong dipolar interaction between $\mathrm{Li}$ ion and paramagnetic spins of Mn ions in the discharged material.

Previous studies have reported that the $\mathrm{Li}^{+} / \mathrm{H}^{+}$exchange occurs as a major charge compensation mechanism on the electrochemical measurements at $55{ }^{\circ} \mathrm{C}$, which is associated with the decomposition of electrolyte solvent on the electrode. ${ }^{34,43,44}$ We observed a small ${ }^{1} \mathrm{H}$ signal at $299 \mathrm{ppm}$, which can be assigned to the intercalated proton in the material during the charge (Fig. S2†) ${ }^{43}$ However, its intensity is very small compared to the ${ }^{1} \mathrm{H}$ signal from the PVDF, the present study suggests that the $\mathrm{Li}^{+} / \mathrm{H}^{+}$exchange seems less significant even at $50{ }^{\circ} \mathrm{C}$.

To confirm the two-phase delithiation model from the atomic scale resolution, we obtained the EELS and HAADF-STEM images for the electrode disassembled at the 50\% SOC (230 $\mathrm{mA} \mathrm{h} \mathrm{g}$ ${ }^{1}$ ). Fig. 4 shows the EELS intensity mapping images for Li, O K- and Mn L-edges. The particle thickness was roughly estimated to be $50-100 \mathrm{~nm}$ from the ratio of the total electron beam intensity and zero-loss intensity. This particle was confirmed not to overlap with the other particles. The inhomogeneous Li distribution strongly supports the coexistence of Li-rich and 
Li-poor regions within a single particle. The relatively homogeneous $\mathrm{O}$ and $\mathrm{Mn}$ intensity distribution indicates that the $\mathrm{Li}$ inhomogeneity does not come from the inhomogeneous particle thickness. The Li mapping also indicates that the Li extraction is not consistent with a simple core-shell or domino-cascade type reaction front models. From the electron energy loss (EEL) spectra it is found that the chemical states of $\mathrm{Mn}$ and $\mathrm{O}$ ions are different between the Li-rich and Li-poor regions (Fig. 4e-g). The Mn L- and M-edge spectra for the Li-rich region are similar in shape and peak top position to those for $\mathrm{MnO}_{2}$, where $\mathrm{Mn}$ ions are tetravalent. The L-edge intensity ratio $L_{3} / L_{2}$, which is used as a criterion of the oxidation state of TM ions, ${ }^{45-47}$ is also close to that for $\mathrm{MnO}_{2}$. The fast Fourier-transformed (FFT) patterns of the HAADF image show diffraction spots indexed with $C 2 / m$, indicating that the Li-rich region remains as $\mathrm{Li}_{2} \mathrm{MnO}_{3}$ (Fig. 5b, inset and S3†). On the other hand, the Li-poor region shows the $\mathrm{Mn} \mathrm{L}$ - and M-edge spectra similar to those for $\mathrm{Mn}_{2} \mathrm{O}_{3}$. The $L_{3} / L_{2}$ ratio is also close to that for $\mathrm{Mn}_{2} \mathrm{O}_{3}$. This suggests that the Li-poor region has a reduced Mn valence state close to trivalent. The FFT image indicates that the Li-poor region consists of cubic $(F d-3 m)$ and/or tetragonal $\left(I 4_{1} / a m d\right)$ spinel phase(s) (Fig. 5d, inset and S3†). These results are consistent with our preliminary EELS and selected area electron diffraction (SAED) measurements on the TEM images acquired for the $\mathrm{Li}_{2} \mathrm{MnO}_{3}$ electrode disassembled at $4.8 \mathrm{~V}$ (Fig. S4b,d†). Also, the O/Mn atomic ratio in the Li-poor region is found to be smaller (by ca. 2.4) than that in the Li-rich region, based on the O K-edge and Mn L-edge EELS intensity ratio (See also Fig. S5a†). Although the chemical composition determined from the EELS intensity is still less accurate, this strongly suggests that some oxygen atoms are removed from the material to be the Li-poor spinel phase during the delithiation process.

The HAADF-STEM image for the Li-rich region shows dumbbell-like atomic lines (-Li-Mn-Mn-) characteristic of TM layer in $\mathrm{Li}_{2} \mathrm{MnO}_{3}$ (Fig. 5c). It also shows the stacking faults along $c$ axis as suggested by the XRD profile for the pristine material. ${ }^{32}$ There is no clear 
evidence of the cation mixing within the TM layer and the Mn migration into the Li layer, although our previous report on the pristine material indicated the cation mixing within the TM layer. $^{32}$ It is possible to speculate that the delithiation easily proceeds from the cation mixing regions, which then transform into the spinel-like framework. The HAADF image for the Li-poor region is smoky in appearance and it is difficult to observe the atomic column lines (Fig. 5d). This would be related to the significant lattice disordering and is consistent with the severe intensity decrease in the XRD profiles on delithiation (Fig. 2). However, on closer inspection the Li-poor region shows the Mn migration into the Li layer (Fig. 5e), which corresponds to the formation of spinel-like structure. ${ }^{29-31}$

We summarise the phase transformation of $\mathrm{Li}_{2} \mathrm{MnO}_{3}$ on the initial charging process. We propose that the delithiation from $\mathrm{Li}_{2} \mathrm{MnO}_{3}$ proceeds in a two-phase reaction;

$$
\mathrm{Li}_{2} \mathrm{MnO}_{3} \rightarrow 1 / 2 \mathrm{Li}_{\delta \sim 0} \mathrm{Mn}_{2-\beta} \mathrm{O}_{4}+1 / 2 \mathrm{O}_{2}+2 \mathrm{Li}^{+}+2 e^{-} \text {(ideal formula). }
$$

Recently, the two-phase delithiation mechanism was suggested for $\mathrm{Li}_{2} \mathrm{MnO}_{3}$ by using Raman spectroscopy and principle component analysis. ${ }^{48}$ In that study, a $\mathrm{MnO}_{2}$-type phase was suggested in the charged material, whereas the other Raman spectroscopy study considered the formation of spinel-type structure. ${ }^{25}$ Here, we emphasise that the resultant spinel phase is not a surface degradation product during the charging process. It is also noteworthy that the chemical composition, especially the $\mathrm{O} / \mathrm{Mn}$ ratio, of the spinel phase is not well fixed, and it is most likely defective. From the EEL spectra, it is found that the Li-poor spinel phase involves the trivalent Mn ions. The Mn L- and O K-edge XAFS spectra also suggested the reduced Mn ions and some contribution of the oxygen in lattice to charge compensation (Fig. S6†). Although the Mn reduction on the charging process is considered to be a consequence of the charge compensation for oxygen vacancy formation, ${ }^{49}$ it may also be associated with the partial oxidation of the lattice oxygen atoms. These results imply that the Li-poor spinel phase, tentatively expressed as 
$\mathrm{Li}_{\delta \sim 0} \mathrm{Mn}_{2-\beta} \mathrm{O}_{4}$, observed on the delithiation from $\mathrm{Li}_{2} \mathrm{MnO}_{3}$ is different from the Li-poor spinel $\mathrm{Li}_{\delta \sim 0} \mathrm{Mn}_{2} \mathrm{O}_{4}$ observed on the delithiation from $\mathrm{LiMn}_{2} \mathrm{O}_{4}$ (Fig. S6†). Similar discussion was done by Phillips et al., who considered the Mn-substoichiometric $\mathrm{Li}_{x} \mathrm{Mn}_{4 / 3} \mathrm{O}_{4}$ spinel in the discharged material. $^{31}$ The recent first-principles calculations suggested that the spinel-like structure is stabilised compared to the pristine layered structure for $\mathrm{Li}_{x} \mathrm{MnO}_{3}$ with low $\mathrm{Li}$ contents. ${ }^{30,50,51}$ Therefore, the layered-to-spinel transformation of $\mathrm{Li}_{\delta \sim 0} \mathrm{MnO}_{3}$ will be thermodynamically plausible. This is the activation mechanism during the $1^{\text {st }}$ charging process accompanying the Mn migration within the structure and the oxygen loss from the structure, where the latter may be kinetically hindered to some extent, resulting in the highly disordered defective structure different from $\mathrm{Li}_{\delta \sim 0} \mathrm{Mn}_{2} \mathrm{O}_{4}$. The discharging process is further complicated. The XRD and NMR results suggest that the reaction expressed above appears partially reversible. The SAED patterns for the samples charged to $4.8 \mathrm{~V}$ and discharged to $2.0 \mathrm{~V}$ at room temperature indicated that the cubic spinel phase transforms back into the monoclinic layered phase (Fig. S4†). Therefore, it is expected that the Mn remigration from the Li layer to TM layer occurs and overall crystal structure reverts to the layered structure during the relithiation in the $1^{\text {st }}$ cycle. This is consistent with the annular bright field (ABF) STEM observation by Wang et al. ${ }^{29}$ On the other hand, the average oxidation state of the Mn ions is close to +3 to +3.5 in the discharged state (Fig. S4d and S6†). Considering the above information and the fact that the discharging capacity reaches only about a half of the charging capacity (Fig. 1), the discharged material consists of layered $\mathrm{LiMnO}_{2}$ with a small fraction of $\mathrm{Li}_{2} \mathrm{MnO}_{3}$, or may be described as partially-disordered $\mathrm{Li}[\mathrm{Li}, \mathrm{Mn}] \mathrm{O}_{2}$.

\subsection{Structural characterisation of $\mathrm{Li}_{2} \mathrm{MnO}_{3}$ after the $20^{\text {th }}$ charge-discharge cycle}

The crystal structures of the active material after the $20^{\text {th }}$ charge-discharge cycle are also examined. Fig. 6 shows the charge-discharge profiles for the $1^{\text {st }}, 2^{\text {nd }}, 5^{\text {th }}, 10^{\text {th }}, 15^{\text {th }}$, and $20^{\text {th }}$ 
cycles. They show the capacity and voltage fading up to the $20^{\text {th }}$ cycle. The profiles are almost identical after the $10^{\text {th }}$ cycle, suggesting that the structural changes are almost completed within the first 10 cycles. The charging and discharging capacities at the $20^{\text {th }}$ cycle are 133 and $130 \mathrm{~mA}$ $\mathrm{h} \mathrm{g}^{-1}$, respectively. The $d \mathrm{Q} / d \mathrm{~V}$ curves and the charge-discharge capacities as a function of cycle number are also shown in Fig. S7†.

The SR-XRD profiles of the cycled materials are shown in Fig. 7. The diffraction profiles for the $2^{\text {nd }}$ charged and discharged samples $\left(\right.$ Sps. \#10,11) are similar to the ones for the $1^{\text {st }}$ charged and discharged samples (Sps. \#5,7), but some peaks become much broader and are significantly reduced in intensity. After the $20^{\text {th }}$ charge-discharge cycle, the discharged sample shows a severely broadened profile (Sp.\#12), and the main peak positions are reasonably close to those of $\mathrm{LiMn}_{3} \mathrm{O}_{4}$ (Fig. $\mathrm{S} 1 \dagger$ ). ${ }^{52}$ The $21^{\text {st }}$ charged sample also shows a broad profile similar to that of the $20^{\text {th }}$ discharged one, but the peak positions are slightly shifted to higher diffraction angles (Sp. \#13). Therefore, the charged sample is considered to be a $\mathrm{Li}$-poor $\mathrm{Li}_{\delta \sim 0} \mathrm{Mn}_{3} \mathrm{O}_{4}$-like phase. This suggests that the pristine layered structure is transformed and gradually stabilised into a spinel-like framework during the multiple delithiation/relithiation processes. This is also supported by the ${ }^{6} \mathrm{Li}$ MAS NMR spectra, where the $\mathrm{Li}$ environment in the pristine $\mathrm{Li}_{2} \mathrm{MnO}_{3}$ structure is completely lost and a new one probably associated with a $\mathrm{Mn}^{3+}$-bearing phase is stabilised in the $20^{\text {th }}$ cycle (Fig. S8†). ${ }^{16}$

To understand the structural origin of the electrochemical fading behaviour, the HAADF-STEM images are acquired for the electrode disassembled at $2.0 \mathrm{~V}$ in the $20^{\text {th }}$ cycle and that at $4.8 \mathrm{~V}$ in the $21^{\text {st }}$ cycle (Fig. 8). Both the discharged and charged materials show the FFT patterns representative of the cubic $(F d-3 m)$ and/or tetragonal $\left(I_{1} / a m d\right)$ spinel phases (Fig. 8 b and e, inset). The atomic column images for both the materials are smoky in appearance, but in several regions the Mn migration into the Li layer representative of the spinel structure can be 
identified. The Mn migration is observed in the bulk regions as well as at the surface regions. Therefore, we conclude that both the discharged and charged materials are completely transformed into the spinel-like structure in the $20^{\text {th }}$ charge-discharge cycle. The previous STEM studies reported that the $\mathrm{Li}_{2} \mathrm{MnO}_{3}$ structure was preserved in the bulk but changed to the spinel and cubic rock-salt structures at the surface for the $\mathrm{Li}_{2} \mathrm{MnO}_{3}$ particle in the electrode disassembled at $2.0 \mathrm{~V}$ after 10 cycles at room temperature. ${ }^{30,31}$ Such a difference among the present and previous studies can be partly attributed to the temperature at which the electrochemical measurements were performed. The charge-discharge cycling at $50{ }^{\circ} \mathrm{C}$ would accelerate the irreversible layered-to-spinel phase transformation in the structure.

The EELS intensity mapping indicates the inhomogeneous $\mathrm{Li}$ distribution in the $20^{\text {th }}$ discharged material (Fig. 9b), suggesting the heterogeneous relithiation in the degraded material. Surprisingly, the EEL and XAFS spectra indicate that both the discharged and charged materials hold the divalent and trivalent Mn ions (Fig. 9e,g,h,j and S9†). Also, they show the lower O/Mn ratios of ca. 1.8 and 1.1, respectively (Fig. S5b and c†).

The previous studies reported that the layered $\mathrm{LiMnO}_{2}$ with the space group of $C 2 / m$ shows the layered-to-spinel transformation during the cycles. ${ }^{53,54}$ Therefore, we conclude that the layered $\mathrm{LiMnO}_{2}$-like structure, which is considered to occur at the end of the initial cycle, is again transformed into the Li-poor spinel structure in the subsequent charging process, and finally the Mn ions are frozen at the Li layer, the layered structure is lost, and the spinel-like framework is stabilised both in the charged and discharged states after multiple cycles. The proposed phase transformation process is summarised in Fig. 10. The spinel phases in the charged and discharged materials have highly disordered and defective structures, and their compositions may be close to $\mathrm{Li}_{\delta \sim 0} \mathrm{Mn}_{3} \mathrm{O}_{4}$ and $\mathrm{LiMn}_{3} \mathrm{O}_{4}$, respectively. It should be noted that the reported charge-discharge profiles of layered $\mathrm{LiMnO}_{2}$ and $\mathrm{LiMn}_{3} \mathrm{O}_{4}$ are different from the present 
curves, ${ }^{53,55}$ the structure, composition, and charge compensation mechanism of the cycled material should be more complicated. These findings suggest that the capacity and voltage fading in $\mathrm{Li}_{2} \mathrm{MnO}_{3}$ during multiple charge-discharge cycles are attributable to the structural stabilisation into the defect spinel phase both in the charged and discharged states, where the lithium reinsertion is suppressed by the structural reorganisation accompanying the oxygen removal and the lower-valence $\mathrm{Mn}$ redox couple $\left(\mathrm{Mn}^{2+} / \mathrm{Mn}^{3+}\right)$ is activated.

\section{Conclusions}

We investigated the delithiation process of $\mathrm{Li}_{2} \mathrm{MnO}_{3}$ during the initial charge-discharge cycle and showed a direct evidence of the layered-to-spinel phase transformation in a two-phase reaction manner on the initial charge. The EELS/HAADF-STEM techniques provide the comprehensive information on elemental distribution, valence state, crystal structure, and visualisation of atomic column images, which indicated the two structural domains consisting of $\mathrm{Li}_{2} \mathrm{MnO}_{3}$ and $\mathrm{Li}$-poor defect spinel phase in a single particle in the electrode sample at the 50\% SOC. Therefore, the electrochemical activation of $\mathrm{Li}_{2} \mathrm{MnO}_{3}$ involves the formation of the spinel phase, which is associated with the oxygen loss from the pristine structure and the spontaneous Mn migration into the vacated Li layer site with the partial oxidation of the lattice oxygen and the reduction of Mn valence. We emphasise that the layered-to-spinel transformation occuring on the initial charge is not a consequence of the structural degradation, but it is the essential activation process of $\mathrm{Li}_{2} \mathrm{MnO}_{3}$. Also, it is confirmed from the ${ }^{1} \mathrm{H}$ NMR that the $\mathrm{Li}^{+} / \mathrm{H}^{+}$exchange is negligible on the electrochemical operation at $50{ }^{\circ} \mathrm{C}$. Although the defect spinel structure would revert back to the layered structure during the initial relithiation, the detailed structure is now different from the pristine $\mathrm{Li}_{2} \mathrm{MnO}_{3}$. It was also found that after the $20^{\text {th }}$ cycle the spinel structure is stabilised in the fully-discharged/charged materials. Such stabilisation of the spinel framework compared to the 
layered structure on $\mathrm{Li}$ reintercalation is considered as the structural degradation where the $\mathrm{Mn}^{2+} / \mathrm{Mn}^{3+}$ redox couple is activated and a limited amount of $\mathrm{Li}$ ions are reintercalated due to the irreversible oxygen loss from the lattice. This corresponds to the capacity and voltage fading in the charge-discharge profile of $\mathrm{Li}_{2} \mathrm{MnO}_{3}$. We believe that the same fading behaviour that has been reported in LMRs is also caused by the layered-to-spinel transformation and its stabilisation during the charge-discharge cycles in the $\mathrm{Li}_{2} \mathrm{MnO}_{3}$-rich domain in LMRs.

\section{Author Contributions Statement}

The manuscript is prepared through contributions of all authors: K.S. and M.O. designed the basic part of this research. T.M. prepared the pristine sample. K.S, O.M. and T.M. performed the SR-XRD measurements. K.S. and M.M. performed the solid-state NMR measurements. K.S. and M.O. planned the STEM measurements. K.Y. performed the soft X-ray XAFS measurements. K.S., M.O., T.M., M.M., K.Y., H.A., and T.O. contributed to the scientific discussion of these results. Y.Uch., T.O., E.M., and Z.O. supervised the research. K.S., M.O., M.M., H.A., and Y.Uk. wrote the manuscript, and all authors contributed to the manuscript reviewing and revisions.

\section{Acknowledgements}

This work was supported by the Research and Development Initiative for Scientific Innovation of New Generation Batteries (RISING) and the Research and Development Initiative for Scientific Innovation of New Generation Batteries II (RISING II) projects from the New Energy and Industrial Technology Development Organization (NEDO), Japan. The authors thank Dr. Yasuhiro Takabayashi and Mr. Yuji Kamishima for their supports on sample preparation and electrochemical measurements. The authors thank Drs. Katomi Fujita and Hiroshi Ozono of Kobelco Research Institute, Inc. for their supports and discussion on STEM observations. The 
authors are grateful to Prof. Iwao Watanabe for his fruitful discussion on the soft X-ray absorption spectroscopy measurements. The authors are also grateful to Mr. Takanori Kobayashi, Dr. Tomoya Kawaguchi and Dr. Hisao Kiuchi for their supports on the synchrotron XRD measurements. The synchrotron XRD measurements were performed with the approval of the Japan Synchrotron Radiation Research Institute (JASRI, Proposal Nos. $2015 B 1014$ and 2016A7601). The model structures in Fig. 10 were drawn with the structure visualisation software VESTA. ${ }^{56}$ 


\section{References}

1 T. Ohzuku, A. Ueda, M. Nagayama, Y. Iwakoshi and H. Komori, Comparative Study of $\mathrm{LiCoO}_{2}, \mathrm{LiNi}_{1 / 2} \mathrm{Co}_{1 / 2} \mathrm{O}_{2}$ and $\mathrm{LiNiO}_{2}$ for 4 Volt Secondary Lithium Cells. Electrochim. Acta, 1993, 38, 1159-1167.

2 M.M. Thackeray, C.S. Johnson, J.T. Vaughey, N. Li and S.A. Hackney, Advances in manganese-oxide ‘composite’ electrodes for lithium-ion batteries. J. Mater. Chem., 2005, 15, 2257-2267.

3 M.M. Thackeray, S.-H. Kang, C.S. Johnson, J.T. Vaughey, R. Benedek and S.A. Hackney, $\mathrm{Li}_{2} \mathrm{MnO}_{3}$-stabilized $\mathrm{LiMO}_{2}(\mathrm{M}=\mathrm{Mn}, \mathrm{Ni}, \mathrm{Co})$ electrodes for lithium-ion batteries. J. Mater. Chem., 2007, 17, 3112-3125.

4 T. Ohzuku, M. Nagayama, K. Tsuji and K. Ariyoshi, High-capacity lithium insertion materials of lithium nickel manganese oxides for advanced lithium-ion batteries: toward rechargeable capacity more than $300 \mathrm{~mA} \mathrm{~h} \mathrm{~g}^{-1}$. J. Mater. Chem., 2011, 21, 10179-10188.

$5 \mathrm{H}$. Yu and H. Zhou, High-Energy Cathode Materials $\left(\mathrm{Li}_{2} \mathrm{MnO}_{3}-\mathrm{LiMO}_{2}\right)$ for Lithium-Ion Batteries. J. Phys. Chem. Lett., 2013, 4, 1268-1280.

6 J. Yan, X. Liu and B. Li, Recent progress in Li-rich layered oxides as cathode materials for Li-ion batteries. RSC Adv., 2014, 4, 63268-63284.

7 J.R. Croy, M. Balasubramanian, K.G. Gallagher and A.K. Burrell, Review of the U.S. Department of Energy’s “Deep Dive” Effort to Understand Voltage Fade in Li- and Mn-Rich Cathodes. Acc. Chem. Res., 2015, 48, 2813-2821.

8 A.K. Shukla, Q.M. Ramasse, C. Ophus, H. Duncan, F. Hage and G. Chen, Unravelling structural ambiguities in lithium- and manganese-rich transition metal oxides. Nat. Commun., 2015, 6:8711, doi: 10.1038/ncomms9711.

9 H. Liu, Y. Chen, S. Hy, K. An, S. Venkatachalam, D. Qian, M. Zhang and Y.S. Meng, 
Operando Lithium Dynamics in the Li-Rich Layered Oxide Cathode Material via Neutron Diffraction. Adv. Energy Mater., 2016, 1502143.

10 P. Strobel and B. Lambert-Andron, Crystallographic and Magnetic Structure of $\mathrm{Li}_{2} \mathrm{MnO}_{3} . J$. Solid State Chem., 1988, 75, 90-98.

11 V. Massarotti, M. Bini, D. Capsoni, A. Altomare and A.G.G. Moliterni, Ab initio Structure Determination of $\mathrm{Li}_{2} \mathrm{MnO}_{3}$ from X-ray Powder Diffraction Data. J. Appl. Cryst., 1997, 30, $123-127$.

12 C.S. Johnson, J.-S. Kim, C. Lefief, N. Li, J.T. Vaughey and M.M. Thackeray, The significance of the $\mathrm{Li}_{2} \mathrm{MnO}_{3}$ component in 'composite' $x \mathrm{Li}_{2} \mathrm{MnO}_{3} \cdot(1-x) \mathrm{LiMn}_{0.5} \mathrm{Ni}_{0.5} \mathrm{O}_{2}$ electrodes. Electrochem. Commun., 2004, 6, 1085-1091.

13 P. Kalyani, S. Chitra, T. Mohan and S. Gopukumar, Lithium metal rechargeable cells using $\mathrm{Li}_{2} \mathrm{MnO}_{3}$ as the positive electrode. J. Power Sources, 1999, 80, 103-106.

14 D.Y.W. Yu, K. Yanagida, Y. Kato and H. Makamura, Electrochemical Activities in $\mathrm{Li}_{2} \mathrm{MnO}_{3}$. J. Electrochem. Soc., 2009, 156, A417-A424.

15 J. Rana, M. Stan, R. Kloepsch, J. Li, G. Schumacher, E. Welter, I. Zizak, J. Banhart and M. Winter, Structural Changes in $\mathrm{Li}_{2} \mathrm{MnO}_{3}$ Cathode Material for Li-Ion Batteries. Adv. Energy Mater., 2014, 4, 1300998.

16 J.R. Croy, J.S. Park, F. Dogan, C.S. Johnson, B. Key and M. Balasubramanian, First-Cycle Evolution of Local Structure in Electrochemically Activated $\mathrm{Li}_{2} \mathrm{MnO}_{3}$. Chem. Mater., 2014, 26, 7091-7098.

17 Z. Lu and J.R. Dahn, Understanding the Anomalous Capacity of $\mathrm{Li} / \mathrm{Li}\left[\mathrm{Ni}_{x} \mathrm{Li}_{(1 / 3-2 x / 3)} \mathrm{Mn}_{(2 / 3-}\right.$ ${ }_{x / 3)} \mathrm{O}_{2}$ Cells Using In Situ X-Ray Diffraction and Electrochemical Studies. J. Electrochem. Soc., 2002, 149, A815-A822.

18 Y. Koyama, I. Tanaka, M. Nagao and R. Kanno, First-principles study on lithium removal 
from $\mathrm{Li}_{2} \mathrm{MnO}_{3}$. J. Power Sources, 2009, 189, 798-801.

19 R. Xiao, H. Li and L. Chen, Density Functional Investigation on $\mathrm{Li}_{2} \mathrm{MnO}_{3}$. Chem. Mater., 2012, 24, 4242-4251.

20 M. Sathiya, K. Ramesha, G. Rousse, D. Foix, D. Gonbeau, A.S. Prakash, M.L. Doublet, K. Hemalatha and J.-M. Tarascon, High Performance $\mathrm{Li}_{2} \mathrm{Ru}_{1-y} \mathrm{Mn}_{y} \mathrm{O}_{3}(0.2 \leq y \leq 0.8)$ Cathode Materials for Rechargeable Lithium-Ion Batteries: Their Understanding. Chem. Mater., 2013, 25, 1121-1131.

21 M. Sathiya, G. Rousse, K. Ramesha, C.P. Laisa, H. Vezin, M.T. Sougrati, M.-L. Doublet, D. Foix, D. Gonbeau, W. Walker, A.S. Prakash, M. Ben Hassine, L. Dupont and J.-M. Tarascon, Reversible anionic redox chemistry in high-capacity layered-oxide electrodes. Nat. Mater., 2013, 12, 827-835.

22 S. Han, Y. Xia, Z. Wei, B. Qiu, L. Pan, Q. Gu, Z. Liu and Z. Guo, A comparative study on the oxidation state of lattice oxygen among $\mathrm{Li}_{1.14} \mathrm{Ni}_{0.136} \mathrm{Co}_{0.136} \mathrm{Mn}_{0.544} \mathrm{O}_{2}, \mathrm{Li}_{2} \mathrm{MnO}_{3}$, $\mathrm{LiNi}_{0.5} \mathrm{Co}_{0.2} \mathrm{Mn}_{0.3} \mathrm{O}_{2}$ and $\mathrm{LiCoO}_{2}$ for the initial charge-discharge. J. Mater. Chem. A, 2015, 3, 11930-11939.

23 M. Oishi, K. Yamanaka, I. Watanabe, K. Shimoda, T. Matsunaga, H. Arai, Y. Ukyo, Y. Uchimoto, Z. Ogumi and T. Ohta, Direct observation of reversible oxygen anion redox reaction in Li-rich manganese oxide, $\mathrm{Li}_{2} \mathrm{MnO}_{3}$, studied by soft $\mathrm{X}$-ray absorption spectroscopy. J. Mater. Chem. A, 2016, 4, 9293-9302.

24 S.F. Amalraj, B. Markovsky, D. Sharon, M. Talianker, E. Zinigrad, R. Persky, O. Haik, J. Grinblat, J. Lampert, M. Schulz-Dobrick, A. Garsuch, L. Burlaka and D. Aurbach, Study of the electrochemical behavior of the "inactive" $\mathrm{Li}_{2} \mathrm{MnO}_{3}$. Electrochim. Acta, 2012, 78, 3239.

25 S.F. Amalraj, L. Burlaka, C.M. Julien, A. Mauger, D. Kovacheva, M. Talianker, B. 
Markovsky and D. Aurbach, Phase Transitions in $\mathrm{Li}_{2} \mathrm{MnO}_{3}$ Electrodes at Various States-of-Charge. Electrochim. Acta, 2014, 123, 395-404.

26 R. Huang and Y. Ikuhara, STEM characterization for lithium-ion battery cathode materials. Curr. Opin. Solid State Mater. Sci., 2012, 16, 31-38.

27 L. Gu, D. Xiao, Y.-S. Hu, H. Li and Y. Ikuhara, Atomic-Scale Structure Evolution in a Quasi-Equilibrated Electrochemical Process of Electrode Materials for Rechargeable Batteries. Adv. Mater., 2015, 27, 2134-2149.

28 D. Qian, C. Ma, K.L. More, Y.S. Meng and M. Chi, Advanced analytical electron microscopy for lithium-ion batteries. NPG Asia Mater., 2015, 7, e193; doi: 10.1038/am.2015.50.

29 R. Wang, X. He, L. He, F. Wang, R. Xiao, L. Gu, H. Li and L. Chen, Atomic Structure of $\mathrm{Li}_{2} \mathrm{MnO}_{3}$ after Partial Delithiation and Relithiation. Adv. Energy Mater., 2013, 3, 13581367.

30 P. Yan, L. Xiao, J. Zheng, Y. Zhou, Y. He, X. Zu, S.X. Mao, J. Xiao, F. Gao, J.-G. Zhang and C.-M. Wang, Probing the Degradation Mechanism of $\mathrm{Li}_{2} \mathrm{MnO}_{3}$ Cathode for Li-Ion Batteries. Chem. Mater., 2015, 27, 975-982.

31 P.J. Phillips, J. Bareño, Y. Li, D.P. Abraham and R.F. Klie, On the Localized Nature of the Structural Transformations of $\mathrm{Li}_{2} \mathrm{MnO}_{3}$ Following Electrochemical Cycling. Adv. Energy Mater., 2015, 5, 1501252.

32 T. Matsunaga, H. Komatsu, K. Shimoda, T. Minato, M. Yonemura, T. Kamiyama, S. Kobayashi, T. Kato, T. Hirayama, Y. Ikuhara, H. Arai, Y. Ukyo, Y. Uchimoto and Z. Ogumi, Dependence of Structural Defects in $\mathrm{Li}_{2} \mathrm{MnO}_{3}$ on Synthesis Temperature. Chem. Mater., 2016, 28, 4143-4150.

33 M.M. Thackeray, A. de Kock and W.I.F. David, Synthesis and Structural Characterization of 
Defect Spinels in the Lithium-Manganese-Oxides System. Mater. Res. Bull., 1993, 28, 1041-1049.

34 A.D. Robertson and P.G. Bruce, The origin of electrochemical activity in $\mathrm{Li}_{2} \mathrm{MnO}_{3}$. Chem. Commun., 2002, 2790-2791.

35 K.R. Morgan, S. Collier, G. Burns and K. Ooi, A ${ }^{6} \mathrm{Li}$ and ${ }^{7} \mathrm{Li}$ MAS NMR Study of the Spinel-type Manganese Oxide $\mathrm{LiMn}_{2} \mathrm{O}_{4}$ and the Rock Salt-type Manganese Oxide $\mathrm{Li}_{2} \mathrm{MnO}_{3}$. J. Chem. Soc. Chem. Commun., 1994, 1719-1720.

36 P. Mustarelli, V. Massarotti, M. Bini and D. Capsoni, Transferred hyperfine interaction and structure in $\mathrm{LiMn}_{2} \mathrm{O}_{4}$ and $\mathrm{Li}_{2} \mathrm{MnO}_{3}$ coexisting phases: A XRD and ${ }^{7} \mathrm{Li}$ NMR-MAS study. Phys. Rev. B, 1997, 55, 12018-12024.

37 Y.J. Lee and C.P. Grey, Determining the Lithium Local Environments in the Lithium Manganates $\mathrm{LiZn}_{0.5} \mathrm{Mn}_{1.5} \mathrm{O}_{4}$ and $\mathrm{Li}_{2} \mathrm{MnO}_{3}$ by Analysis of the ${ }^{6} \mathrm{Li}$ MAS NMR Spinning Sideband Manifolds. J. Phys. Chem. B, 2002, 106, 3576-3582.

38 Y.J. Lee, F. Wang and C.P. Grey, ${ }^{6} \mathrm{Li}$ and ${ }^{7} \mathrm{Li}$ MAS NMR Studies of Lithium Manganate Cathode Materials. J. Am. Chem. Soc., 1998, 120, 12601-12613.

39 Y.J. Lee and C.P. Grey, ${ }^{6} \mathrm{Li}$ Magic-Angle Spinning (MAS) NMR Study of Electron Correlations, Magnetic Ordering, and Stability of Lithium Manganese(III) Oxides. Chem. Mater., 2000, 12, 3871-3878.

40 C.P. Grey and Y.J. Lee, Lithium MAS NMR studies of cathode materials for lithium-ion batteries. Solid State Sci., 2003, 5, 883-894.

41 B.M. Meyer, N. Leifer, S. Sakamoto, S.G. Greenbaum and C.P. Grey, High Field Multinuclear NMR Investigation of the SEI Layer in Lithium Rechargeable Batteries. Electrochem. Solid-State Lett., 2005, 8, A145-A148.

42 N. Dupré, J.-F. Martin, D. Guyomard, A. Yamada and R. Kanno, Detection of surface layers 
using ${ }^{7}$ Li MAS NMR. J. Mater. Chem., 2008, 18, 4266-4273.

43 A.D. Robertson and P.G. Bruce, Mechanism of Electrochemical Activity in $\mathrm{Li}_{2} \mathrm{MnO}_{3}$. Chem. Mater., 2003, 15, 1984-1992.

44 A.R. Armstrong, A.D. Robertson and P.G. Bruce, Overcharging manganese oxides: Extracting lithium beyond $\mathrm{Mn}^{4+}$. J. Power Sources, 2005, 146, 275-280.

45 J.H. Rask, B.A. Miner and P.R. Buseck, Determination of Manganese Oxidation States in Solids by Electron Energy-Loss Spectroscopy. Ultramicroscopy, 1987, 21, 321-326.

46 J.H. Paterson and O.L. Krivanek, ELNES of 3d Transition-Metal Oxides. Ultramicroscopy, 1990, 32, 319-325.

47 Z.L. Wang, J.S. Yin and Y.D. Jiang, EELS analysis of cation valence states and oxygen vacancies in magnetic oxides. Micron, 2000, 31, 571-580.

48 R.E. Ruther, H. Dixit, A.M. Pezeshki, R.L. Sacci, V.R. Cooper, J. Nanda and G.M. Veith, Correlating Local Structure with Electrochemical Activity in $\mathrm{Li}_{2} \mathrm{MnO}_{3}$. J. Phys. Chem. C, 2015, 119, 18022-18029.

49 K.J. Carroll, D. Qian, C. Fell, S. Calvin, G.M. Veith, M. Chi, L. Baggetto and Y.S. Meng, Probing the electrode/electrolyte interface in the lithium excess layered oxide $\mathrm{Li}_{1.2} \mathrm{Ni}_{0.2} \mathrm{Mn}_{0.6} \mathrm{O}_{2}$. Phys. Chem. Chem. Phys., 2013, 15, 11128-11138.

50 E. Lee and K.A. Persson, Structural and Chemical Evolution of the Layered Li-Excess $\mathrm{Li}_{x} \mathrm{MnO}_{3}$ as a Function of Li Content from First-Principles Calculations. Adv. Energy Mater., 2014, 4, 1400498.

51 J.-M. Lim, D. Kim, Y.-G. Lim, M.-S. Park, Y.-J. Kim, M. Cho and K. Cho, The origins and mechanism of phase transformation in bulk $\mathrm{Li}_{2} \mathrm{MnO}_{3}$ : first-principles calculations and experimental studies. J. Mater. Chem. A, 2015, 3, 7066-7076.

52 M.M. Thackeray, W.I.F. David, P.G. Bruce and J.B. Goodenough, Lithium Insertion into 
Manganese Spinels. Mater. Res. Bull., 1983, 18, 461-472.

53 Y. Shao-Horn, S.A. Hackney, A.R. Armstrong, P.G. Bruce, R. Gitzendanner, C.S. Johnson and M.M. Thackeray, Structural Characterization of Layered $\mathrm{LiMnO}_{2}$ Electrodes by Electron Diffraction and Lattice Imaging. J. Electrochem. Soc., 1999, 146, 2404-2412.

54 A.R. Armstrong, N. Dupre, A.J. Paterson, C.P. Grey and P.G. Bruce, Combined Neutron Diffraction, NMR, and Electrochemical Investigation of the Layered-to-Spinel Transformation in $\mathrm{LiMnO}_{2}$. Chem. Mater., 2004, 16, 3106-3118.

55 M.A. Lowe, J. Gao and H.D. Abruña, In operando X-ray studies of the conversion reaction in $\mathrm{Mn}_{3} \mathrm{O}_{4}$ lithium battery anodes. J. Mater. Chem. A, 2013, 1, 2094-2103.

56 K. Momma and F. Izumi, VESTA 3 for three-dimensional visualization of crystal, volumetric and morphology data. J. Appl. Crystallogr., 2011, 44, 1272-1276. 
Figures and Figure captions

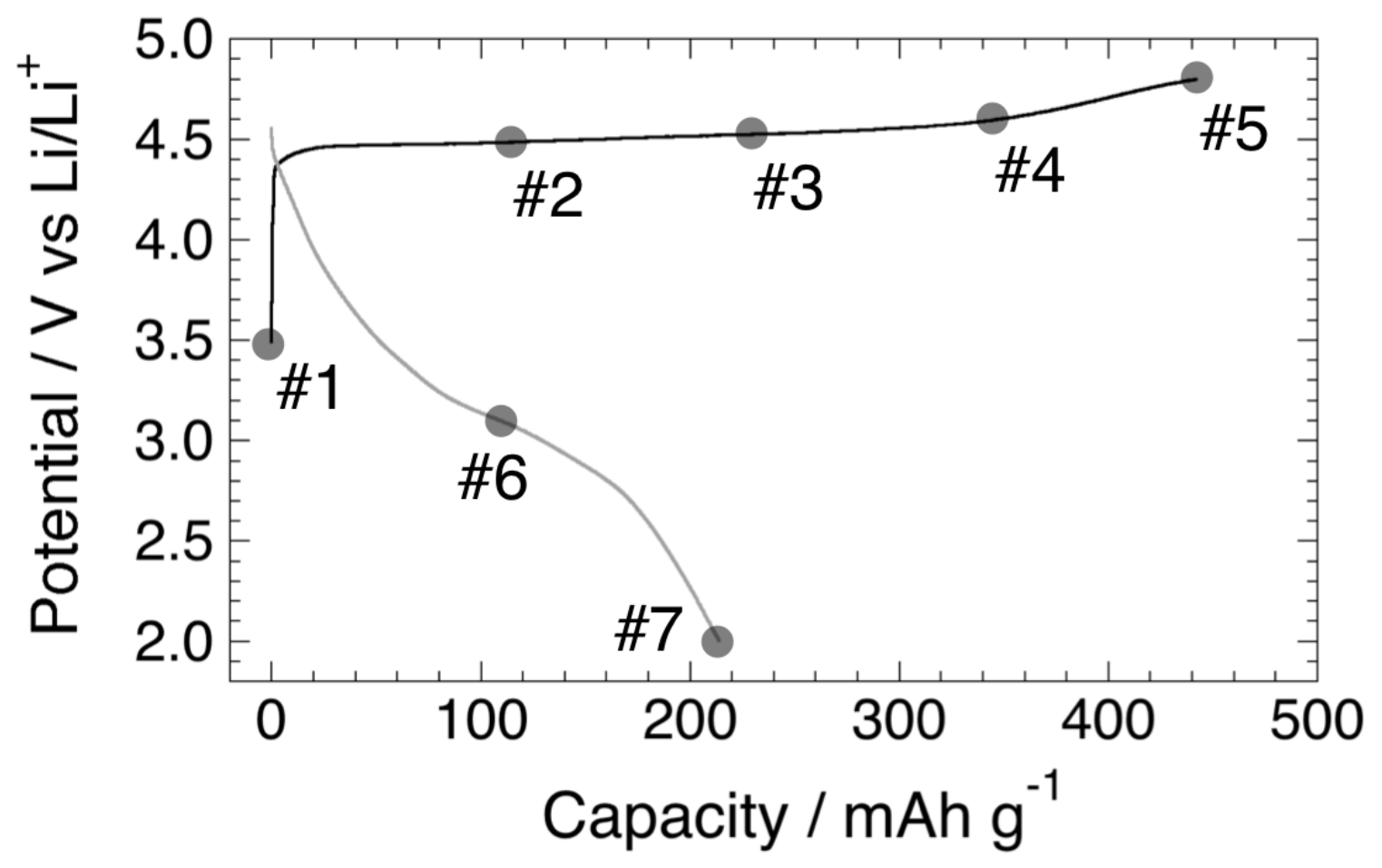

Fig. 1. Charge-discharge profiles of the $\mathrm{Li} / \mathrm{Li}_{2} \mathrm{MnO}_{3}$ cell for the $1^{\text {st }}$ cycle. The electrochemical measurements were performed at $50{ }^{\circ} \mathrm{C}$ between 4.8 and $2.0 \mathrm{~V}$ vs. $\mathrm{Li} / \mathrm{Li}^{+}$with a constant current of $23 \mathrm{~mA} / \mathrm{g}$. The sampling points are marked on the figure and listed in Table S1. 


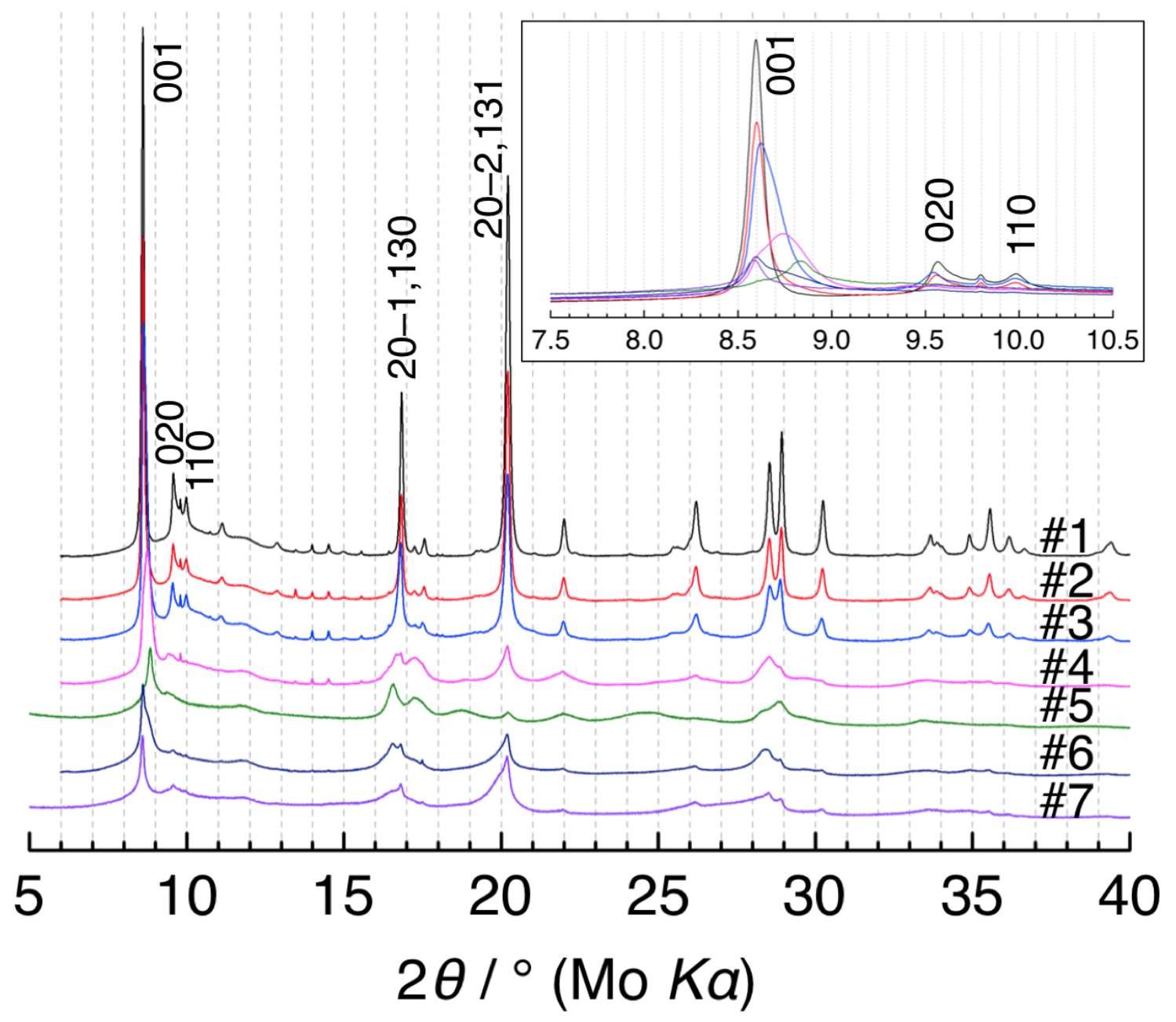

Fig. 2. SR-XRD profiles of the $\mathrm{Li}_{2} \mathrm{MnO}_{3}$ electrode for the $1^{\text {st }}$ cycle. The wavelength is converted to that of Mo Ka radiation. The strongest 001 diffraction peak is enlarged in the inset. The sample numbers are described in Fig. 1. 


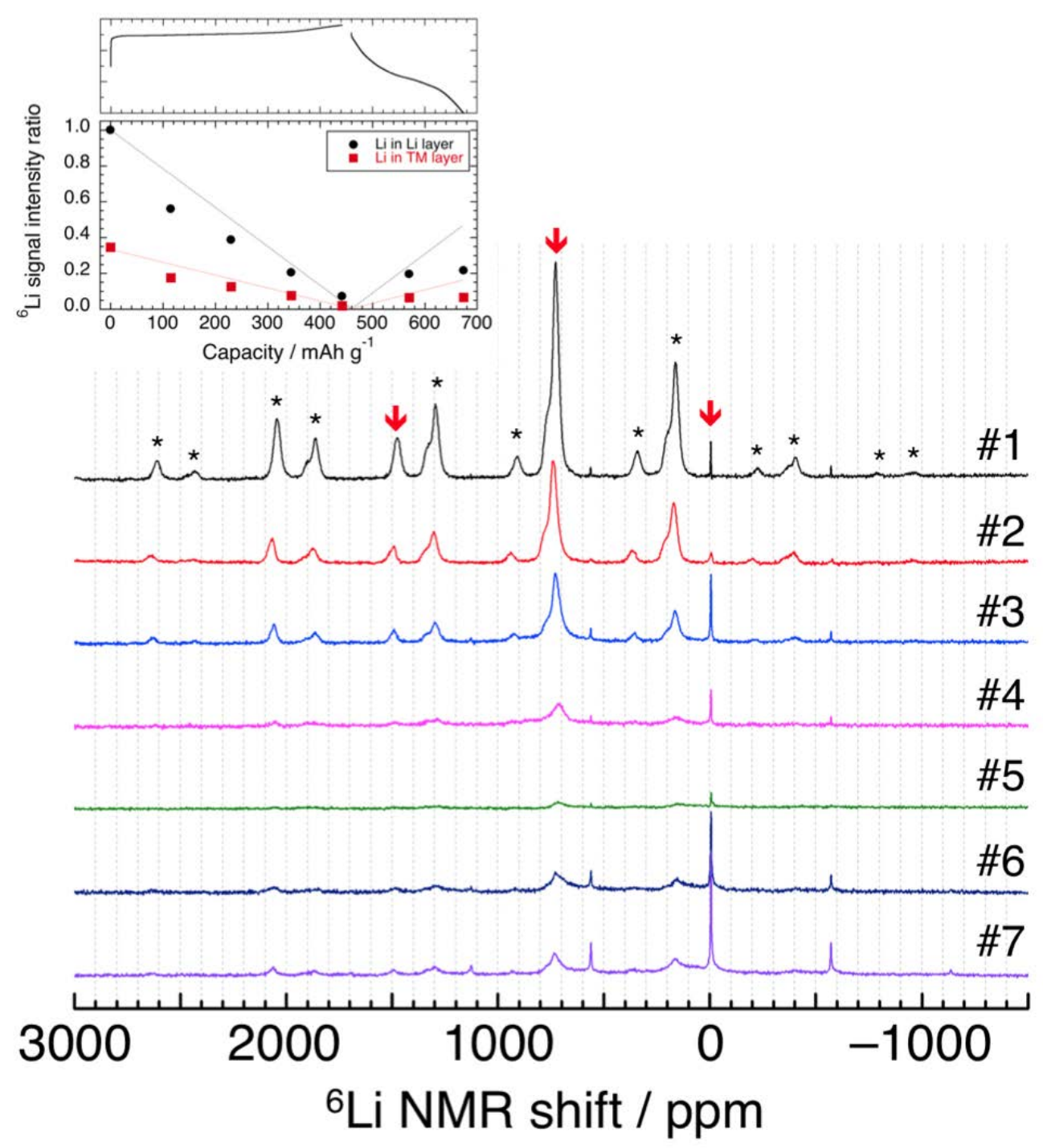

Fig. 3. ${ }^{6} \mathrm{Li}$ MAS NMR spectra of the $\mathrm{Li}_{2} \mathrm{MnO}_{3}$ electrode for the $1^{\text {st }}$ cycle. The sample numbers are described in Fig. 1. The signal intensities are normalised to the scan numbers and sample weights in the rotors. Isotropic signals and their spinning sidebands are marked with arrows and asterisks on the spectrum \#1, respectively. Intensity variation of the ${ }^{6} \mathrm{Li}$ NMR signals along with the potential profile is shown in the inset. The ${ }^{6} \mathrm{Li}$ signal in the $\mathrm{Li}$ layer is normalised to 1.0 in the pristine $\mathrm{Li}\left[\mathrm{Li}_{1 / 3} \mathrm{Mn}_{2 / 3}\right] \mathrm{O}_{2}$. The signal intensities are integrated including sideband manifolds. The straight lines are guides to the eye. 

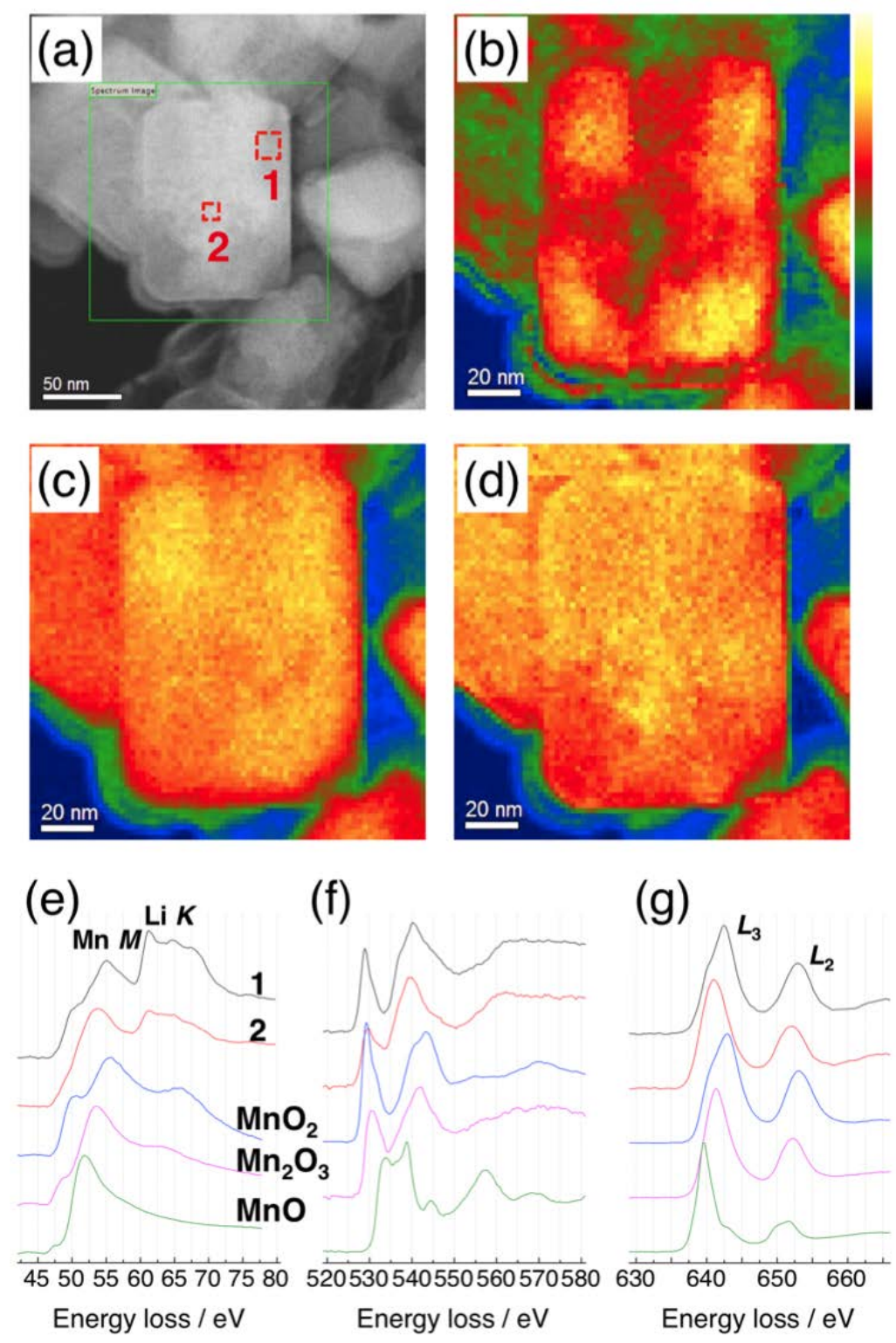

Fig. 4. EELS mapping images and EEL spectra for the electrode sample disassembled at the 50\% SOC in the $1^{\text {st }}$ cycle. (a) HAADF-STEM image, (b) Li K-edge, (c) O K-edge, and (d) Mn L-edge intensity maps. The EEL spectra at (e) Mn M-edge + Li K-edge, (f) O K-edge, and (g) Mn L-edge. The spectra 1 and 2 are acquired from the regions 1 and 2 (corresponding to the Li-rich and Li-poor regions) in (a), respectively. The reference spectra of $\mathrm{MnO}_{2}\left(\mathrm{Mn}^{4+}\right), \mathrm{Mn}_{2} \mathrm{O}_{3}\left(\mathrm{Mn}^{3+}\right)$, and $\mathrm{MnO}\left(\mathrm{Mn}^{2+}\right)$ are also shown. 


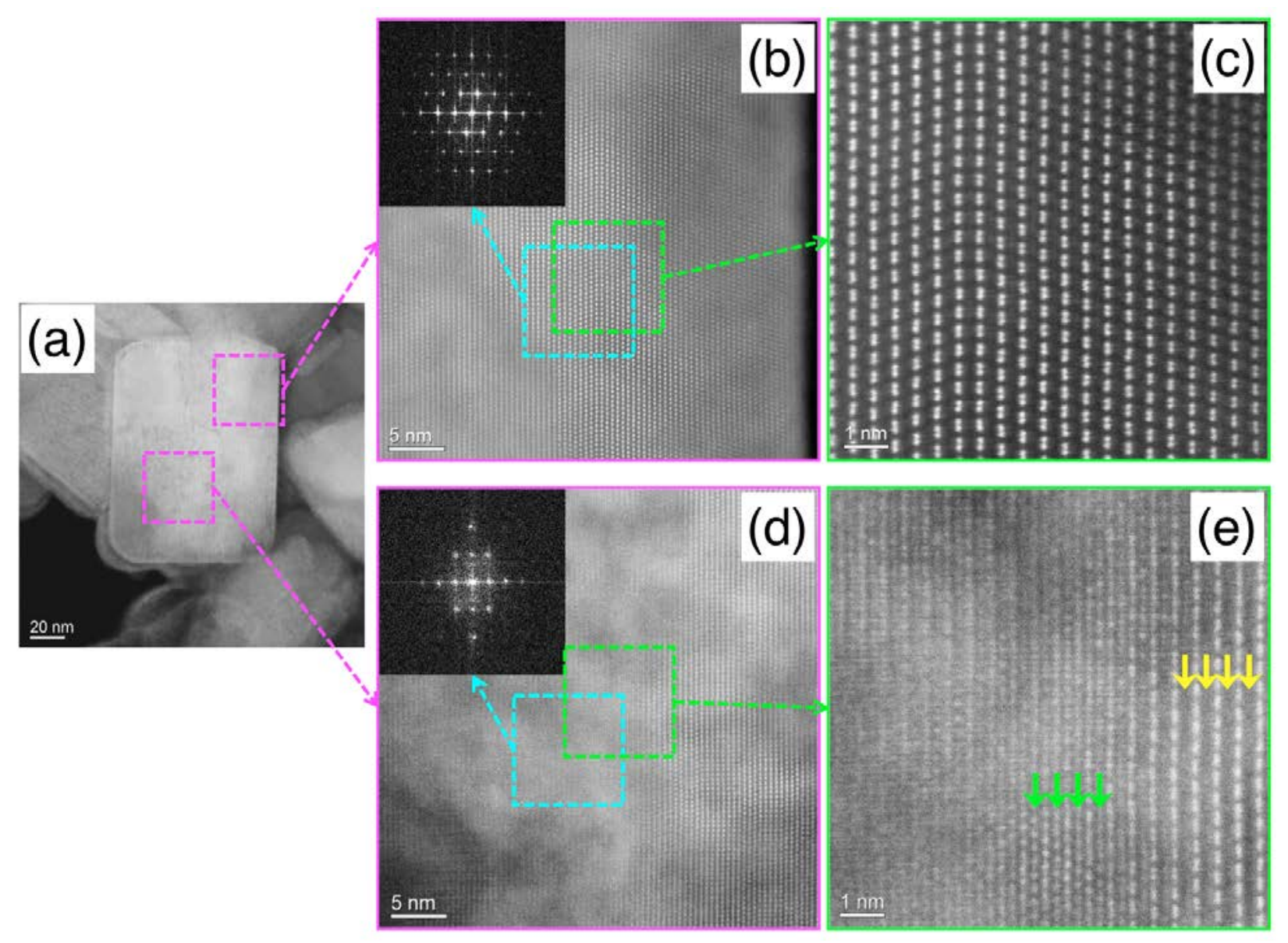

Fig. 5. HAADF-STEM images acquired along the $[110]_{\text {monoclinic }}$ zone axis for the electrode sample disassembled at the $50 \%$ SOC in the $1^{\text {st }}$ cycle. (a) HAADF image of a selected single particle, (b,c) HAADF image of a selected area corresponding to the Li-rich region and (d,e) Li-poor region, respectively. The FFT patterns of the HAADF images are shown in (b) and (d). The $\mathrm{Li}$ and $\mathrm{Mn}$ atoms in the Li layers are marked with yellow and light green arrows, respectively (light Li atoms, if present, are invisible in the HAADF image). 


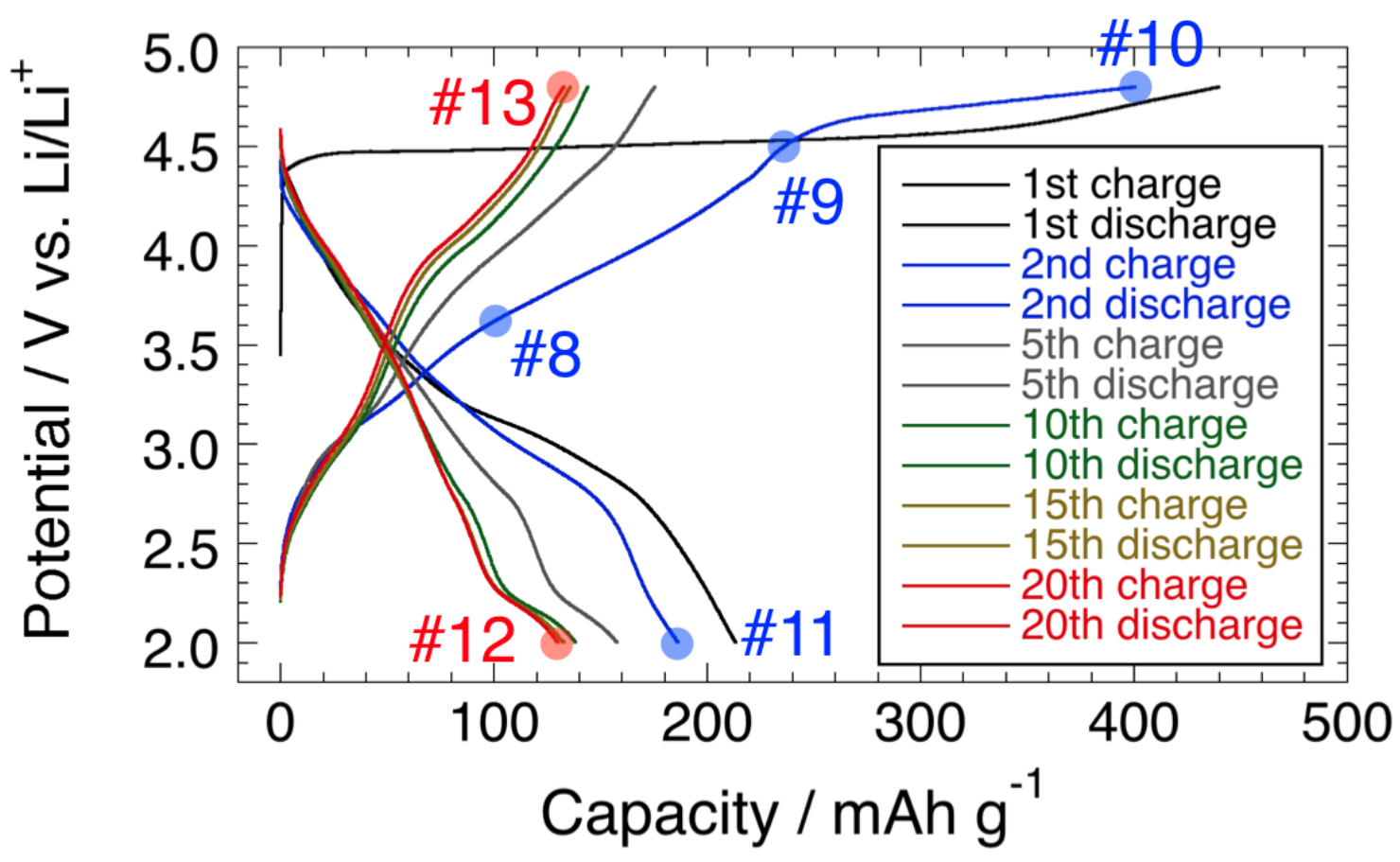

Fig. 6. Charge-discharge profiles of the $\mathrm{Li} / \mathrm{Li}_{2} \mathrm{MnO}_{3}$ cell for the $1^{\text {st }}, 2^{\text {nd }}, 5^{\text {th }}, 10^{\text {th }}, 15^{\text {th }}$, and $20^{\text {th }}$ cycles. The electrochemical measurements were performed at $50^{\circ} \mathrm{C}$ between 4.8 and $2.0 \mathrm{~V}$ with a constant current of $23 \mathrm{~mA} / \mathrm{g}$. The sampling points are marked on the figure and listed in Table S1 (The sample \#13 for the electrode charged to $4.8 \mathrm{~V}$ in the $21^{\text {st }}$ cycle is marked on the $20^{\text {th }}$ charge). 


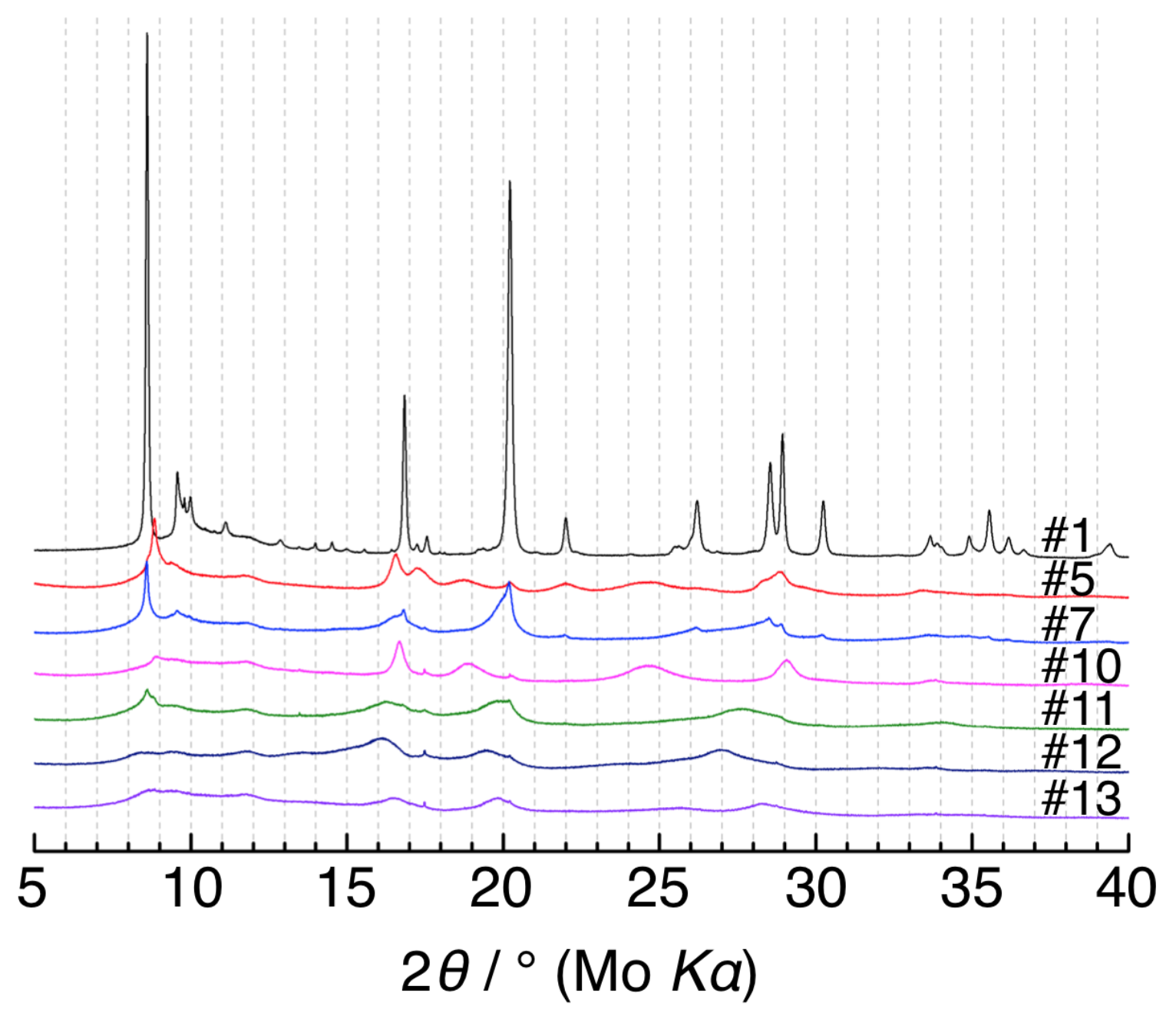

Fig. 7. SR-XRD profiles of the $\mathrm{Li}_{2} \mathrm{MnO}_{3}$ electrode for the $1^{\text {st }}, 2^{\text {nd }}$ cycles, $20^{\text {th }}$ discharge, and $21^{\text {st }}$ charge. The wavelength is converted to that of Mo $K \alpha$ radiation. The sample numbers are described in Fig. 1 and 6. 

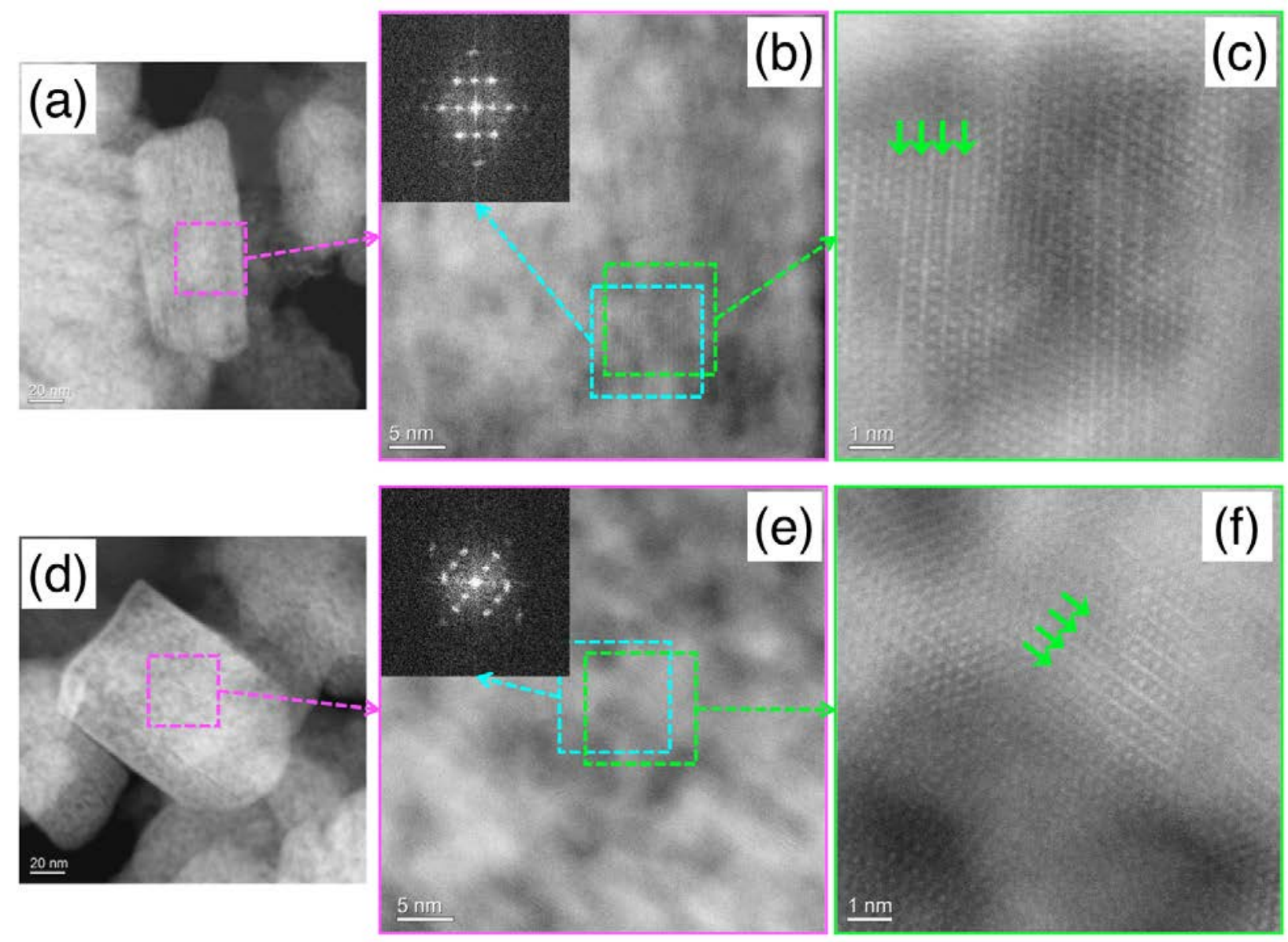

Fig. 8. HAADF-STEM images for the electrode samples disassembled at $2.0 \mathrm{~V}$ (upper panels; a,b,c) and $4.8 \mathrm{~V}$ (lower panels; d,e,f) in the $20^{\text {th }}$ and $21^{\text {st }}$ cycle, respectively. The FFT patterns of the HAADF images are shown in (b) and (e). The Mn atoms in the Li layers are marked with light green arrows. 

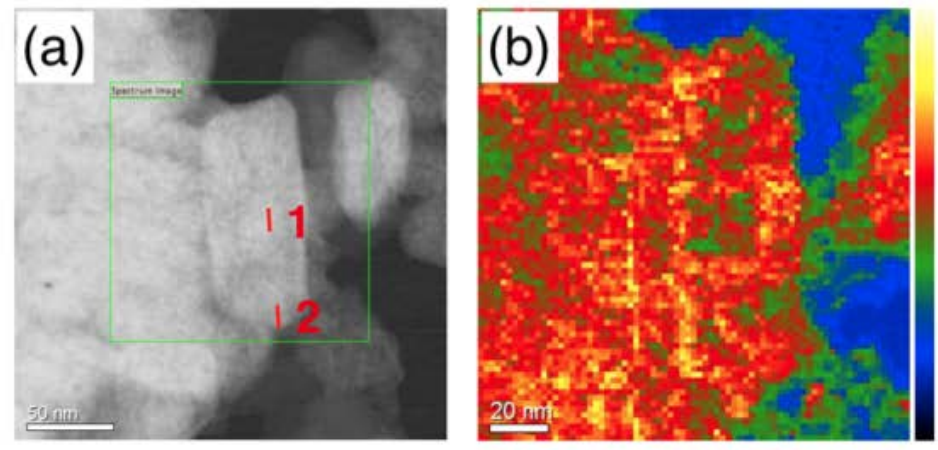

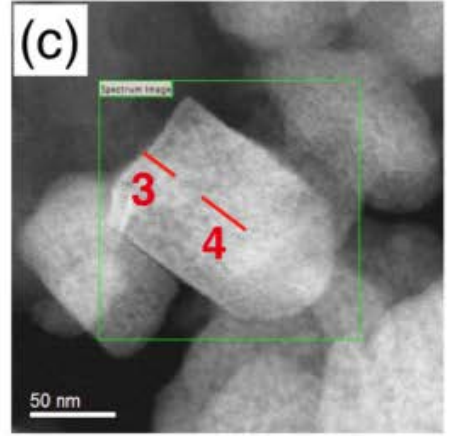

(e)

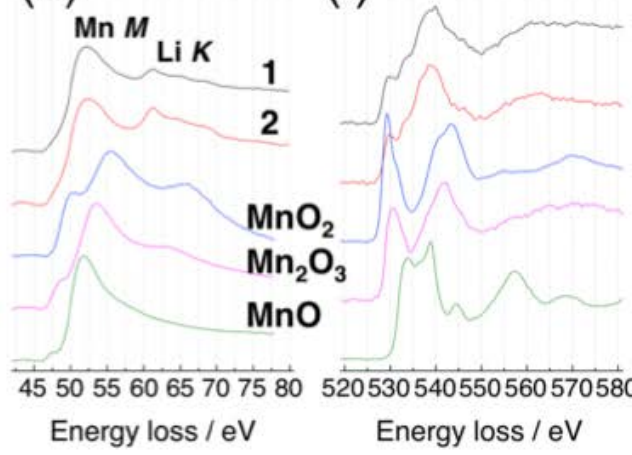

(h)

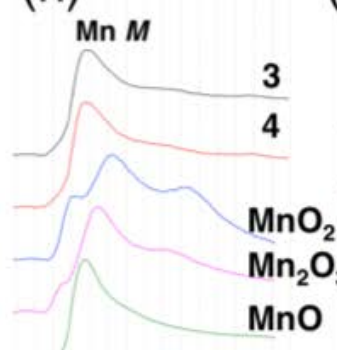

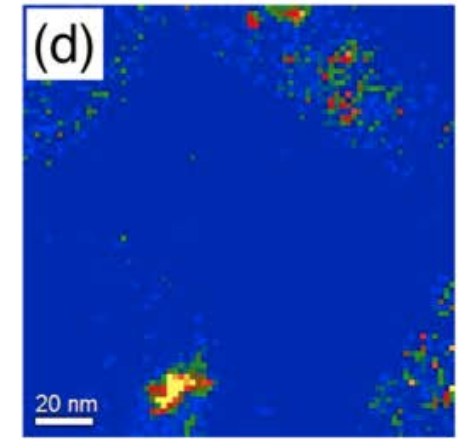

(g)

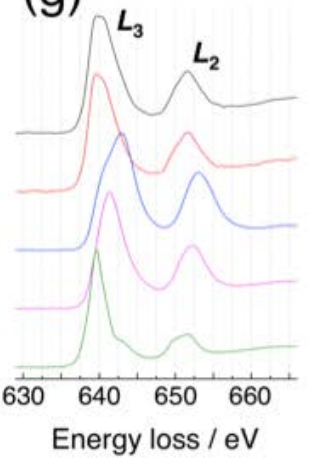

(j)

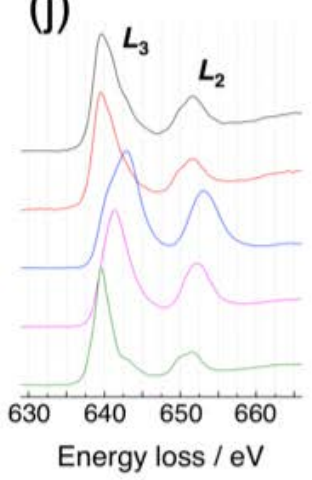

Fig. 9. EELS mapping images and EEL spectra for the electrode samples disassembled at $2.0 \mathrm{~V}$ and $4.8 \mathrm{~V}$ in the $20^{\text {th }}$ and $21^{\text {st }}$ cycle, respectively. (a) HAADF-STEM image and (b) Li K-edge 
map for the sample at $2.0 \mathrm{~V}$. (c) HAADF-STEM image and (d) Li K-edge map for the sample at 4.8 V. The EEL spectra at (e) Mn M-edge + Li K-edge, (f) O K-edge, and (g) Mn L-edge for the sample at 2.0 V, (h) Mn M-edge + Li K-edge, (i) O K-edge, and (j) Mn L-edge for the sample at 4.8 V. The spectra 1-4 are acquired from the lines 1-4 in (a) and (c). The reference spectra of $\mathrm{MnO}_{2}\left(\mathrm{Mn}^{4+}\right), \mathrm{Mn}_{2} \mathrm{O}_{3}\left(\mathrm{Mn}^{3+}\right)$, and $\mathrm{MnO}\left(\mathrm{Mn}^{2+}\right)$ are also shown. 


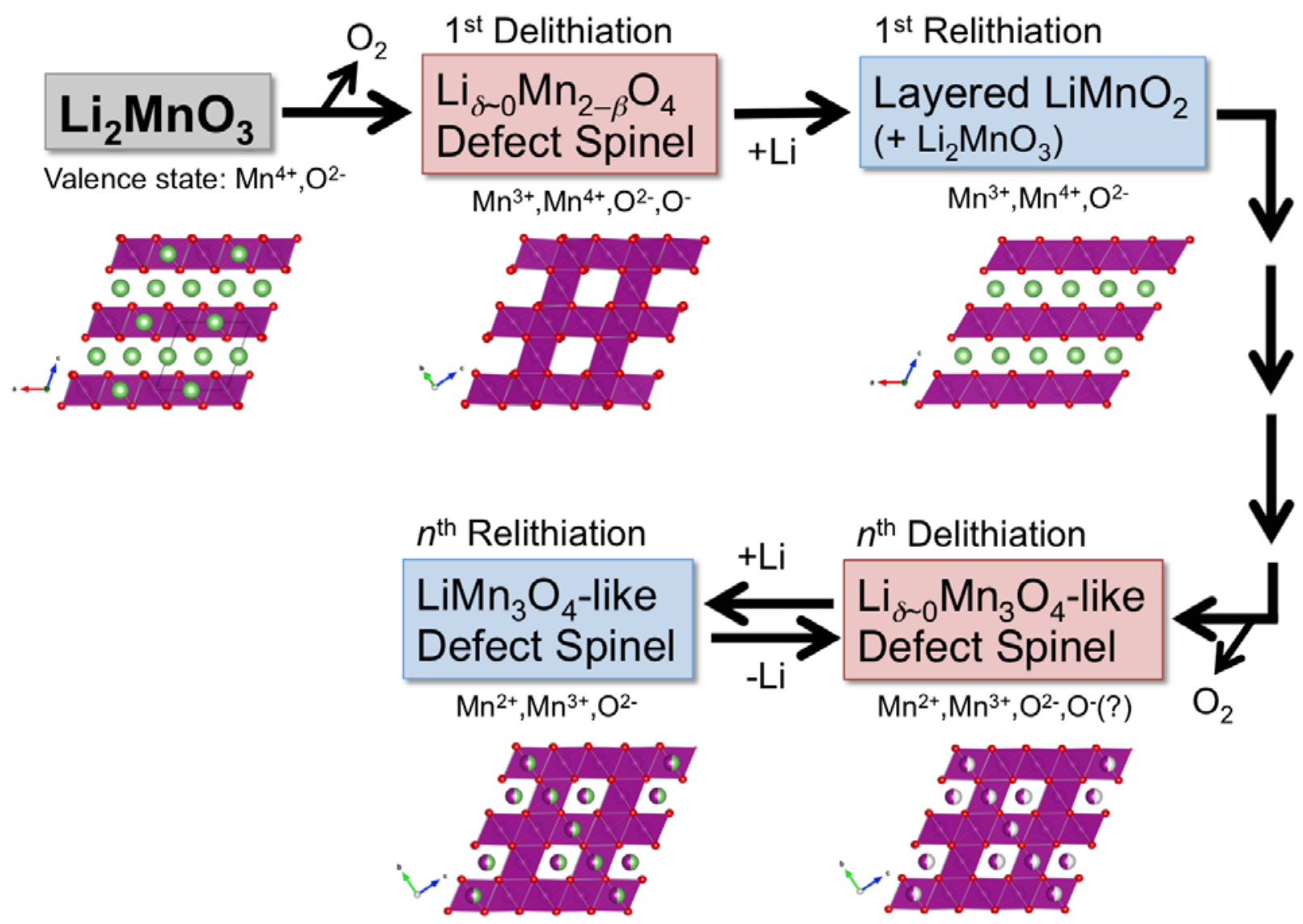

Fig. 10. Schematic illustration of the layered-to-spinel phase transformation in $\mathrm{Li}_{2} \mathrm{MnO}_{3}$ during the initial cycle and after the multiple cycles. 


\section{Table of Contents}

Direct Observation of Layered-to-Spinel Phase Transformation in $\mathrm{Li}_{2} \mathrm{MnO}_{3}$ and Spinel

\section{Structure Stabilised after the Activation Process}

Keiji Shimoda, Masatsugu Oishi, Toshiyuki Matsunaga, Miwa Murakami, Keisuke Yamanaka, Hajime Arai, Yoshio Ukyo, Yoshiharu Uchimoto, Toshiaki Ohta, Eiichiro Matsubara, Zempachi Ogumi

The layered-to-spinel phase transformation in $\mathrm{Li}_{2} \mathrm{MnO}_{3}$ during the initial charge occurs in the two-phase reaction process within a single particle.
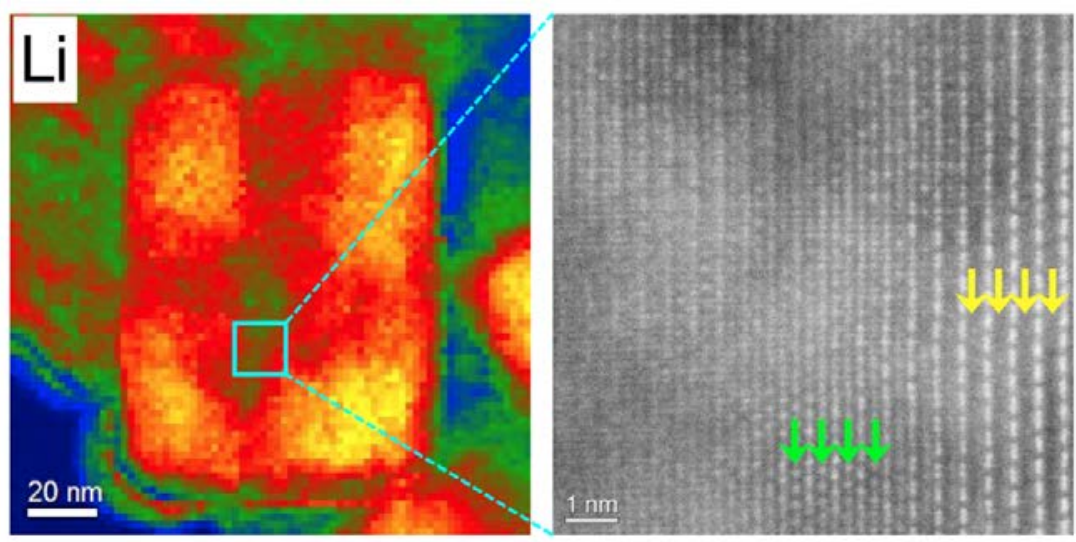